\title{
Epidemiology of Low Back Pain
}

\author{
Laxmaiah Manchikanti, MD
}

Low back pain is a symptom that cannot be validated by an external standard. It is a disorder with many possible etiologies, occurring in many groups of the population, and with many definitions. Low back pain is a common problem, with a prevalence in the United States ranging from $8 \%$ to $56 \%$. It is estimated that $28 \%$ experience disabling low back pain sometime during their lives, $14 \%$ experience episodes lasting at least 2 weeks, $8 \%$ of the entire working population will be disabled in any given year, and the lifetime prevalence of low back pain is $65 \%$ to $80 \%$.

It is believed that most episodes of low back pain will be short-lived and that $80 \%$ to $90 \%$ of attacks of low back pain resolve in about 6 weeks, irrespective of the administration or type of treatment. However, multiple studies in the late 90 s showed recurrent or chronic low back pain, evaluated at 3 months, 6 months, or 12 months, ranging from $35 \%$ to $79 \%$.

Risk factors of low back pain are multifactorial, with many possible etiologies. Multiple risk factors of low back pain and lower-extremity pain include physical factors, social demographic characteristics, habits, and psychosocial factors. This review will discuss the epidemiology of low back pain, with emphasis on frequency, causes, and consequences of low back pain; the influence of age, gender, morphologic characteristics, and genetics; and the influence of occupational, mechanical, social, habitual, and psychological factors.

Keywords: Low back pain, epidemiology, genetic predisposition, risk factors, smoking, elderly, obesity.
Low back pain is an important clinical, social, economic, and public health problem affecting the population indiscriminately. It is a disorder with many possible etiologies, occurring in many groups of the population, and with many definitions. Consequently, the vast literature available on low back pain is not only heterogeneous but also contradictory. By definition, low back pain is a symptom that cannot be validated by an external standard, the symptom being what a person reports (1-9). Thus, the study of the epidemiology of low back pain is a murky field, even though human beings have had backaches throughout recorded history; and the advances in knowledge and high resources spent on the study of low back pain are increasing. Numerous modalities of therapeutic interventions are available for treatment of chronic low back pain: surgery, drugs, manipulation, physical therapy, behavior therapy, and neural blockade continue to spark debate among professionals, with regard to their effectiveness in managing

From Pain Management Center of Paducah, Paducah, KY. Dr. Manchikanti is medical director of Pain Management Center of Paducah. Address correspondence: Laxmaiah Manchikanti, MD, 2831 Lone Oak Road, Paducah, KY 42003 chronic low back pain $(1,10-16)$. Yet an astonishing agreement exists among professionals with regard to the enormity of chronic low back pain and its impact on society (1-17). This review will describe the epidemiologic evidence of low back pain, with an emphasis on its frequency, causes, and consequences; the influence of age, gender, morphologic characteristics, and genetics; and the influence of occupational, mechanical, social, habitual, and psychological factors.

\section{EPIDEMIOLOGY}

Epidemiology is defined as the study of the distribution of disease in the population and the application of this study to control health problems (18). In the case of low back pain, epidemiology investigates how its frequency varies by age, gender, race, and location and how the frequency changes over time. Epidemiology provides an understanding of the natural history of low back pain, which is relevant and essential for the rational planning for healthcare programs and also provides a standard to which the efficacy of various treatments may be verified. Further, epidemiology also provides the link between pain and the individual or external factors, which in a sense allows risk 
factors to be identified and minimized. The two most basic concepts of epidemiology are incidence and prevalence. Incidence is defined as the rate at which healthy people develop a new symptom or disease over a specified period of time, which is dependent solely on the rate at which the disease occurs. However, in contrast to incidence, prevalence is a measure of the number of people in the population who have a symptom or disease at a particular point in time. The prevalence of back pain, for example, is a measure of all those with back pain identified during a certain period, regardless of whether the problem began during or before the survey. Thus, prevalence is a product of both incidence and duration of the disease.

Three most common types of studies published in literature are: cohort studies, case-control studies, and prevalence studies (19). Cohort studies typically follow a group of "healthy" people forward in time to assess disease outcome after risk factors have already been measured (19). Case-control studies use people selected on the basis of outcome status; risk factors are assessed after the fact. Although more prone to bias than cohort studies, case control studies are more common in back pain research because of the ease of examining several risk factors simult- aneously and the expense of cohort studies (19). Prevalence studies use a random sample of people collected at a single point in time; consequently there is no predetermined number of "cases" and "controls," their numbers depending on the prevalence of disease and exposures in the samples (19).

\section{FREQUENCY OF LOW BACK PAIN}

Information on the prevalence or incidence of low back pain is available from numerous sources, including patient interviews or questionnaires, clinical studies, insurance, and hospital data. The quality of the data is variable based on the primary purpose of the investigation, the population studied, and the definition of back pain. Methodological problems in the study of the epidemiology of back pain include recollection of the symptoms, which are subject to recall bias; analysis of Workers' Compensation cases or industrial populations, which may not be generalized to the population in general; and analyses of administrative databases, which depend on the recorded diagnosis for patients with complaints of back pain, which may be underreported or emphasized $(1-8,11)$.

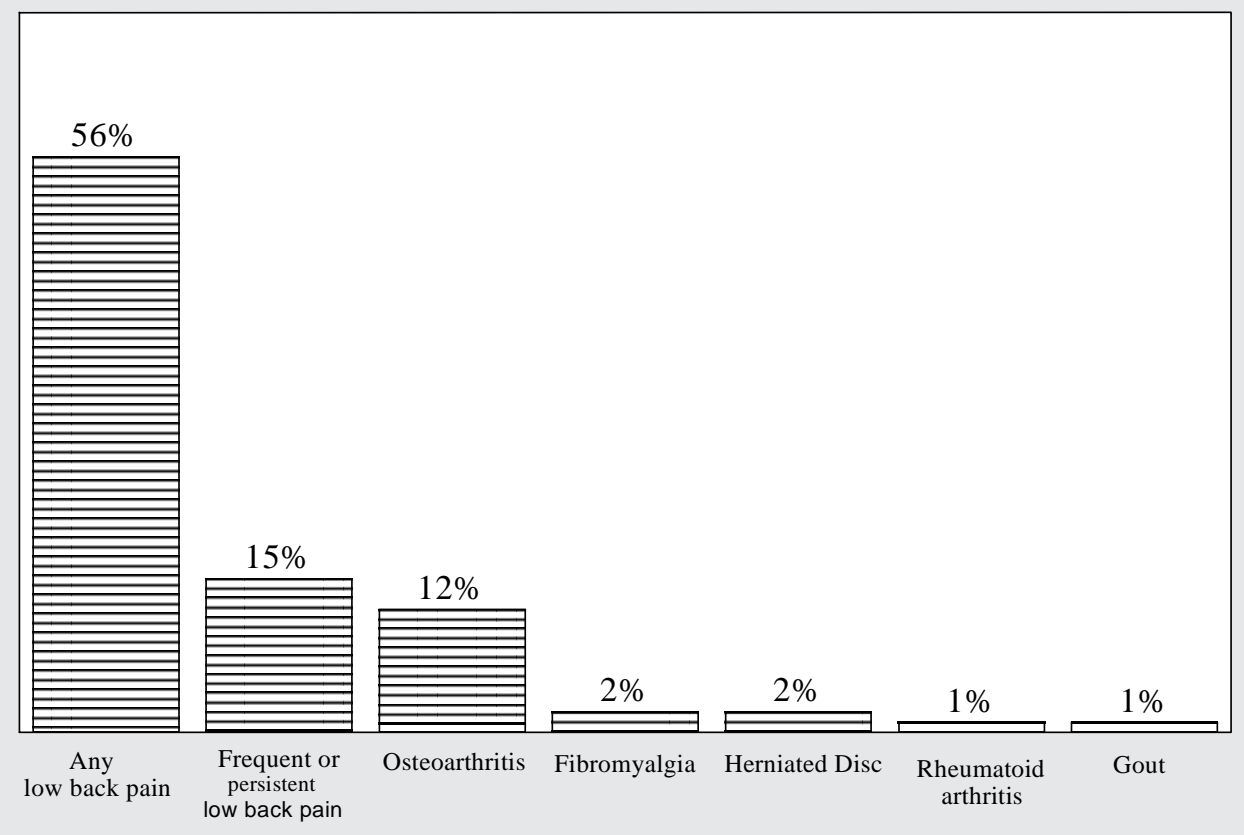

Fig. 1. Low back pain ranks No. 1 in musculoskeletal disorders.

Modified and adapted from Lawrence and colleagues (3). 
It is estimated that episodes of low back pain, that are frequent or persistent have been reported in $15 \%$ of the US population, with a lifetime prevalence of $65 \%$ to $80 \%$ (3) (Fig. 1). It is also stated that $28 \%$ of the US industrial population will experience disabling low back pain at some time and $8 \%$ of the entire working population will be disabled in any given year, contributing to $40 \%$ of all lost work days. Recent estimates of costs, morbidity, and mortality of occupational injury or illnesses in the United States showed that the total direct costs ( $\$ 65$ billion) plus indirect costs ( $\$ 106$ billion) were estimated to be $\$ 171$ billion, with injuries costing \$145 billion and illnesses \$26 billion (17). Studies showed the 1-year prevalence of back pain in the United States to be a highly variable, from $10 \%$ to $56 \%(2,20-26)$.

In an extensive review of the international literature on the incidence of disabling low back pain, Nachemson (27) reported that the problem of low back pain was even greater in Canada, Great Britain, the Netherlands, and Sweden, in comparison to the United States and Germany. This analysis showed that the percentage of work force affected varied from $2 \%$ to $8 \%$, with days of absence per patient per year ranging from 9 days in the United States, to 10 days in West Germany, to 20 days in Canada, to 25 days in the Netherlands, to 30 days in Great Britain, and to 40 days in Sweden.

Epidemiological data is scarce on low back pain in the elderly and children. Systematic review of the literature of back pain in the elderly showed the prevalence to range from $13 \%$ to $51 \%$ (7). Similarly, the studies of pain in childhood also indicate that low back pain has a relatively high prevalence during school years, variable from $12 \%$ to as high as $51 \%(8,26)$.

Table 1: Prevalence of back pain in general population ranked by severity and disability.

\begin{tabular}{lc}
\hline Pain Grade & Percent \\
\hline Grade 1 & $47 \%$ \\
Low pain intensity and disability & \\
Grade 2 & $12 \%$ \\
High pain intensity and low disability & \\
Grade 3 and 4 & $13 \%$ \\
High pain intensity with moderate and severe disability & \\
Total & $72 \%$ \\
\hline Data modified and adapted from Cassidy et al (30)
\end{tabular}

In contrast to low back pain, the incidence of radicular pain with herniated nucleus pulposus has been reported in approximately $25 \%$ of patients with back problems. Overall, disc herniation is presumed to account for fewer than $30 \%$ of cases of low back pain and perhaps as few as $1 \%$ $(2,3-25,28,29)$.

Cassidy and colleagues (30) assessed the 6-month prevalence of chronic low back pain and its impact on general health in the Canadian population. Eighty-four percent of respondents reported lifetime prevalence. The results showed that $47 \%$ of patients reported grade 1 pain (low pain intensity/low disability); $12 \%$, grade 2 pain (high pain intensity/low disability); $13 \%$ grade 3 (high pain intensity/moderate disability); and grade 4 (high pain intensity/ severe disability) pain and disability (Table 1). They also reported that grade 1 low back pain was more common in the younger population, while older age groups reported a higher incidence of grade $3 / 4$ pain. The study also reported that over $10 \%$ of the people responding to the mail questionnaires reported having disabling back pain in the previous 6-month period. Barsky and Borus (31) reported that, "Epidemiologic studies of ambulatory practice, survey of public attitudes, and historical examination of medical practices all suggest that people are increasingly bothered by and disabled by distress and discomforts that in the past were deemed less important and less worthy of medical attention." Gureje and coworkers (4) in a World Health Organization study on primary care of persistent pain and well-being, reported that back pain topped the list of the three most among the three most commonly reported anatomical pain sites in order of frequency, followed by headache, and joint pain. They reported a combined prevalence of persistent pain for all centers across the world as being $22 \%$, with prevalence rates varying from $5 \%$ to $33 \%$.

In a review of the literature on the prevalence of low back pain in adults, Loney and Stratford (5) critically evaluated 18 studies, of which only three were considered as being high quality, showing a point prevalence ranging from $14 \%$ to $29 \%$ and a lifetime prevalence ranging from $59 \%$ to $84 \%$. These studies included the studies by Cassidy and coworkers (30) (Saskatchewan, Canada), with a 29\% point prevalence, 69\% 6-month prevalence, and 84\% lifetime prevalence; Hillman and coworkers (32) (Bradford, United Kingdom), with a point prevalence of $19 \%$, 1-year prevalence of 39\%, and lifetime prevalence of 59\%; and finally, Biering-Sorensen (33) (Grostrup, Denmark), with a point prevalence of $14 \%, 1$-year prevalence of $45 \%$, and lifetime prevalence of $62 \%$. Leboeuf-Yde and Lauritsen (6) 
also reviewed the prevalence of low back pain in the literature from 26 Nordic studies from 1954 through 1993, with 10 of the 26 population-based epidemiological surveys on the occurrence of low back pain in the Nordic countries fulfilling a minimum of $75 \%$ of the methodological criteria. The estimate of the prevalence of low back pain in the United States by Lawrence and colleagues (3) was derived from the National Arthritis Data Work Group, which showed an annual prevalence of low back pain in $56 \%$ a lifetime prevalence of $70 \%$, and a low back pain ranking as No. 1 (Fig. 1).

\section{RECURRENT OR CHRONIC LOW BACK PAIN}

Duration of back pain and its chronicity have been topics of controversy. It is believed that most of these episodes will be short-lived, with $80 \%$ to $90 \%$ of attacks resolving in about 6 weeks, irrespective of the administration or type of treatment; and $5 \%$ to $10 \%$ of patients developing persistent back pain $(34,35)$. However, this concept has been questioned, as the condition tends to relapse, so most patients will experience multiple episodes. In an evaluation of the prognosis of low back pain in general practice in Amsterdam, consisting of 15 general practitioners evaluating for a period of 2 years, it was reported that $35 \%$ of the population experienced low back pain for 12 weeks to 12 months and $10 \%$ experienced pain after 1 year (36). In another prospective report of the outcome of low back pain in general practice, while the annual cumulative consultation rate among adults in the practice was only $6 \%$ and $59 \%$ of the patients had only one consultation, $32 \%$ had repeat consultations 3 months after the initial consultation. Of those interviewed at 3 and 12 months' followup, only $21 \%$ and $25 \%$, respectively, had completely recovered in terms of pain and disability (37). Croft and coworkers (37) concluded that the results were consistent with the interpretation that $90 \%$ of patients with low back pain in primary care will have stopped consulting with symptoms within 3 months, even though most will still be experiencing low back pain and related disability 1 year after consultation. Carey and colleagues (38) showed that chronic low back pain affected $3.9 \%$ of the North Carolina population, with $34 \%$ considering themselves permanently disabled and $52 \%$ assessing their overall health as fair to poor. Carey and coworkers (39) also showed that rates of recurrence of low back pain were substantial; functionally disabling recurrence rates varied between $8 \%$ and $14 \%$ between 3 to 6 months, and $20 \%$ to $35 \%$ between 6 to 22 months. Meidema and colleagues (40) determined the proportion of patients with back pain in whom chronic back problems developed after a follow-up of 7 years, to identify determinants of the chronicity, showing that "chronic back pain problems" developed in $28 \%$ of the patients. These patients reported more pain, higher levels of medical resource consumption, worse health outcomes, and lower labor force participation. They concluded that, even after a follow-up of 7 years, the proportion of people with chronic back problems was high. Von Korff and coworkers (41) also showed the presence of recurrent or chronic low back pain at the end of 1 year. Thomas and colleagues (42) followed 180 patients with new onset of back pain over an 18-month period, of which $34 \%$ reported disabling back pain. They reported that $73 \%$ reported disabling back pain at 1 week, $48 \%$ at 3 months, and $42 \%$ at 12 months. Table 3 demonstrates the prevalence of chronicity of low back pain.

Grades 3 and 4 categories of back pain with disability were reported in $13 \%$ of the population in Canada (30). Davis (15) showed that from 1979 to 1981 to 1988 to 1990 , the rate of hospitalizations with lumbar spine surgery increased over $33 \%$ in each sex, with a rate for lumbar fusion surgery increasing more than $60 \%$ in each sex, the rate for lumbar disc surgery increasing $40 \%$ among men and $21 \%$

Table 2: Chronicity of low back pain

\begin{tabular}{lccc}
\hline \multicolumn{1}{c}{ Author(s) } & Year of Publication & 3 months & 12 months \\
\hline Anderson and Svensson (35) & 1983 & $20 \%$ & $10 \%$ \\
Van Den Hoogen et al (36) & 1997 & $35 \%$ & $35 \%$ \\
Croft et al (37) & 1998 & $79 \%$ & $75 \%$ \\
Carey et al (38) & 1999 & N/A & $20 \%$ to $35 \%$ \\
Meidema et al (40) & 1998 & N/A & $28 \%$ \\
Thomas et al (42) & 1999 & $48 \%$ & $42 \%$ \\
\hline
\end{tabular}

N/A $=$ Not available 
among women, and the rate for lumbar exploration/decompression surgery increasing more than $65 \%$ in each sex. Carey and colleagues (38) also reported that during their evaluation, at least $10 \%$ of the patients underwent surgery in North Carolina.

Various analysts have tried to relate the development of back pain to clinical, radiologic, psychological, and psychosocial factors (43). During the past 50 to 60 years, various explanatory models of back pain adopted by the medical profession have exhibited swings between the mechanical/postural and the behavioral/psychological (4349). Roland and Morris (50), in a study of the natural history of low back pain conducted in a general practice setting, unequivocally concluded: "Psychological factors are not of great importance in the majority of new presentations of back pain in general practice - the increased incidence of psychological abnormalities found in patients attending a hospital is a result of long-standing pain." Thus, they suggested that psychological morbidity is a consequence of back pain rather than a contributory factor to the development of the condition. Klenerman and colleagues (44), in an evaluation of the prediction of chronicity in patients with an acute type of low back pain in a general practice setting, studied 300 patients, with results showing that patients who had not recovered by 2 months were those who went on to become chronic low back pain patients. Burton and coworkers (51) studied psychosocial predictors of outcome in acute and subchronic low back trouble in 252 patients presenting to primary care and concluded that early identification of psychological problems is important in understanding and hopefully preventing the progression to chronicity in low back trouble. Thomas and colleagues (42) also showed that persistence of symptoms was associated with "premorbid" factors, which included high levels of psychological distress, poor self-rated health, low levels of physical activity, smoking, dissatisfaction with employment, and factors related to the episode of low back pain, widespread pain, and restriction in spinal mobility. However, the multivariate model was based on six factor-identified groups whose likelihood of persistent symptoms ranged widely from $6 \%$ to $70 \%$. Gatchel and coworkers (52) showed the presence of "... a robust psychosocial disability factor that is associated with those injured workers who are likely to develop chronic low back pain disability problems." However, they also concluded that preinjury or concomitant psychopathology does not appear to predispose patients to chronic pain disability, although high rates of psychopathology have been shown in chronic low back pain.
Croft and coworkers (53), in a prospective study of 4,501 adults from 18 to 75 years in age, concluded that symptoms of psychological distress in individuals without back pain predict the subsequent onset of new episodes of low back pain.

\section{RISK FACTORS OF LOW BACK PAIN}

Low back pain is a multifactorial disorder with many possible etiologies. Consequently, determining risk factors becomes a difficult task. To analyze the various risk factors of low back pain and dissect the $20^{\text {th }}$-century healthcare enigma, many epidemiologic studies have focused on risk factors for low back pain, attempting to analyze occupational, nonoccupational, and psychosocial factors (54-57). Hence, evidence from a single study, no matter how well designed and executed, is never enough on its own to decide if a risk factor is causal or not (19). A multitude of determinants of low back pain and sciatica include physical factors such as heavy physical strain, frequent lifting, postural stress, and vibration; social demographic characteristics and individual factors such as lifestyle and physical capacity, gender, age, race, genetic factors, height, and weight; habits such as smoking and alcohol consumption; poor general health; and, finally, psychosocial factors. In addition, many of the proposed risks factors have a high prevalence in the general asymptomatic population, further confounding the situation.

\section{Physical Factors}

Heavy physical strain, frequent lifting, vibration, and postural stress are likely to result in disc degeneration, low back pain, and sciatica.

Occupational Risk Factors: The relationship between occupational risk factors and low back pain is not simple because exposure is usually difficult and sometimes impossible to quantify (58-71). Occupational low back pain in industry is a major problem, with prevalences of back pain in the working population varying from $12 \%$ to $41 \%$, depending on the profession, with a mean prevalence of $27 \%$ in the Netherlands (72). In the United States, stateby-state surveys show that occupational low back pain constitutes $9 \%$ to $26 \%$ of all industrial insurance claims and $26 \%$ to $42 \%$ of all wage replacement and health-care costs (73). The prevalence and risk of occupational low back pain in the United States with high physical demands are high (74-76). However, Murphy and Volinn (77) reported that the US estimate of the annual low back pain 
claims rate decreased 34\% between 1987 and 1995, while the annual low back pain claims costs during the same time decreased $58 \%$.

It is also difficult to assess the effect of occupation on each individual, as different individuals in the same occupation perform different jobs, instead of all performing the same job and thus have variable exposures. Similarly, misconceptions may be developed with regards to healthy worker effect, as healthy workers may stay in the same occupation and job; whereas workers with low back pain may leave a job and move to a less physically taxing job, thus, shifting the prevalence of low back pain from heavy industries to light industries. Still another problem is understanding the differences between heavy and light industries. Traditional beliefs suggested that heavy physical jobs required high energy demand, whereas light jobs required low energy demand. However, many low-energy jobs are static in nature, which is an inherent risk factor for low back pain. Tables 3 and 4 demonstrate the 10 highest-and lowest-cost occupations, ranked by a total annual cost of job-related injuries and illnesses (78). Not only the incidence of low back pain but also lumbar disc degeneration was shown to be effected by the occupational

Table 3: Highest-cost occupations in the United States ranked by total annual cost of job-related injuries and illnesses.

\begin{tabular}{clc}
\hline Rank & \multicolumn{1}{c}{ Description } & $\begin{array}{c}\text { Total Annual } \\
\text { Cost in } \\
\text { Millions (US \$) }\end{array}$ \\
\hline 1 & Heavy truck drivers & 365 \\
2 & Nonconstruction laborers & 331 \\
3 & Machine operators, not specified & 260 \\
4 & Occupations not classified & 239 \\
5 & Janitors and cleaners & 226 \\
6 & Nursing aides, orderlies and attendants & 205 \\
7 & Construction laborers & 147 \\
8 & Assemblers & 139 \\
9 & Retail sales workers & 130 \\
\hline 10 & Miscellaneous machine operators & 130 \\
\hline
\end{tabular}

Adapted and modified from Leigh and Miller (78) load (79).

Heavy Physical Work: Several investigators showed an increase in absences (sick days) due to low back pain and also an increase in low back symptoms in individuals performing physically heavy work (70, 71, 80-87). Heavy physical work was strongly associated with the occurrence of low back pain, with highest prevalence of low back pain being present in men with physically heavy professions $(71,80,81)$. Lloyd and colleagues $(81)$ reported a lifetime prevalence of $69 \%$ low back pain and sciatica in miners in contrast to $58 \%$ in office workers, with a 3-month prevalence of $35 \%$ and $26 \%$, respectively. Leigh and Sheetz (87), using a US quality-of-employment survey for 1972 through 1973 data, reported that physically heavy work, particularly farming, was associated with increased levels of low back pain. Higher reports of disc herniations also were reported in physically demanding occupations $(65,66,83,88)$. However, other studies are less clear, as they did not find any differences in prevalence of disc herniation between heavy and light work $(68,84)$.

In a prospective, nested case-control study during a 24year period, it was shown that $46 \%$ of the subjects be-

Table 4: Lowest-cost occupations ranked by total annual cost of job-related injuries and illnesses with a total annual cost of $\$ 13$ to 14 Million (US dollars).

\begin{tabular}{cl}
\hline Rank & \multicolumn{1}{c}{ Description } \\
\hline 1 & Messengers \\
2 & Miscellaneous textile machine operators \\
3 & Laundering and dry-cleaning-machine operators \\
4 & Stationary engineers \\
5 & Painting and paint-spraying machine operators \\
6 & Teacher's aides \\
7 & Tool and diemakers \\
8 & Automobile body and related repairers \\
9 & Vehicle washers and equipment cleaners \\
10 & Machinery maintenance occupations \\
\hline
\end{tabular}

Adapted and modified from Leigh and Miller (78) 
came patients with low back pain (89). Authors of this study concluded that sedentary work or heavy physical workload was associated with the occurrence of low back pain among both women and men (89). The concurrent presence of whole-body vibration and low influence over work conditions among women and of overtime work and poor social relations among men increased the risk for low back pain.

Static Work Postures: Many studies indicate an increased risk of low back pain in individuals with predominantly sitting work postures, while a similar number of studies disagree with this conclusion $(22,67,88,90)$. It was reported that men spending more than half their work day in a car show a three fold increase in risk of disc herniation, which may be due to the combined effects of sitting and vibration (91-95). In addition, it was also reported that individuals with sitting or standing jobs occupying most of the workday had an increased risk of low back pain (96).

Bending, Twisting, and Lifting: The association between low back pain and bending, twisting, and lifting was established in a large number of studies $(22,62,67,81,92$, 95-99). It was reported that frequent bending and twisting were the most frequent cause of back injuries in England (49). The frequency of low back pain after lifting is variable from $15 \%$ to $64 \%(61,69,81,90,92,95,96$, 100-102). Sudden unexpected maximum efforts, as well as lifting in combination with lateral bending and twisting were found to be particularly harmful $(96,97)$. Chaffin and Park (61) reported eight times higher incidence of low back injuries in workers involved in heavy manual lifting compared to sedentary work.

Vibration: Whole-body vibration has been reported to be associated with back pain. Seidel and Heide (103) analyzed the relevant literature in 1986, on the long-term effects of whole-body vibration in 43,000 workers exposed to whole-body vibration and 24,000 persons in control groups. The results indicated an increased health risk of the spine and of the peripheral nervous system after intense long-term whole-body vibration. Holshof and Zanten (104) reviewed epidemiologic studies of whole-body vibration and low back pain in 1987. They concluded that low back pain, disc degeneration, and herniated lumbar disc has the most frequently reported adverse effects. In a 1998 review of whole-body vibration and low back pain, Lings and Leboeuf-Yde (105), which included 53 articles, concluded that while experimental data supported the hypothesis that whole-body vibration can have a negative effect on the spine, these studies failed to offer a quantitative specification of the association between exposure and effect. They also concluded that epidemiological studies have shown drivers to have an increased prevalence of low back pain, probably in a dose-related fashion, postulating that long-term exposure to whole-body vibration can contribute to back disorders. Bovenzi and Hulshof (106) in a 1999 publication, reviewed 45 articles published between 1986 and 1997. The findings of 17 selected studies and the results of the meta-analysis showed that wholebody vibration is associated with an increased risk of low back pain, sciatica, and lumbar intervertebral disc disorders. However, they concluded that the epidemiologic evidence was not sufficient to outline a clear exposureresponse relationship between vibration and low back pain. Increased prevalence of low back pain in drivers of various vehicles including airplanes secondary to vehicular vibration has been reported $(65,107-116)$. A survey among men train operators suggested that workers in a sedentary position with exposure to whole-body vibration were at a special risk for low back pain (65). However, a study of tractor operators showed no correlation between mean duration of tractor driving and back apin compared to persons who were not tractor drivers (66). Evaluation of back pain in bus drivers in Denmark showed that the prevalence of frequent low back pain was $57 \%$ compared to $40 \%$ in the control group (115). Similarly, in a study in California, back and neck pain was shown to be present in $81 \%$ of bus drivers (116). Increased levels of low back pain were also reported in the steel industry $(117,118)$. It was shown that truck driving increased the risk of disc herniation by a factor of four, while tractor driving and car commuting increased the risk by a factor of two (111). In addition, it was also shown that the risk of disc herniation was related to the type of vehicle, indicating significant differences between different brands of vehicles (66). A survey among men crane operators suggested that workers in a sedentary position with exposure to whole-body vibration were at a special risk for low back pain (112). It was shown that, in bus drivers, both physical work load and psychosocial factors, including extended uninterrupted driving, frequency of job problems, high psychosocial demands, low job satisfaction, and low supervisory support were simultaneously independently associated with back pain (113).

\section{Psychosocial Work Factors}

Several psychological work factors implicated in low back pain include worker satisfaction, attitude toward the employer, job satisfaction, quality of interactions between the 
worker and his or her supervisor, poor employee appraisal rating, and monotony at work $(93,102,119-124)$. Bigos et al (120) and Skovron et al (121) in two large scale prospective studies from the United States and Belgium respectively, showed that job dissatisfaction is a significant risk factor for the onset of low back pain. Thomas and colleagues (42), by collecting data on risk factors before the onset of the pain, have shown that the presence of persistent low back pain is not only determined by clinical factors associated with pain, but also by the premorbid state. However, in a study of incidence and risk factors of low back pain in middle-aged farmers, it was concluded that mental stress did not predict unspecified low back pain or sciatic pain (124).

\section{INDUSTRY-SPECIFIC LOW BACK PAIN}

Surveys of various types of occupations show wide variations in the incidence and prevalence of low back pain related to specific industries. Leigh and Miller (78) ranked multiple occupations based on the costs of job-related injuries and diseases, with heavy truck drivers occupying the number one position in terms of high risk and messengers occupying the number one position in terms of lowest-cost occupation. Surprisingly, most of the high cost per employee jobs, such as production helpers, laborers, janitors, nursing orderlies, driver-sales workers, truck drivers, polishing machine operators, kitchen-machine operators, assemblers and others, are not generally regarded as dangerous or high-risk jobs. Similarly, some of the lowrisk jobs, such as messengers, laundry and dry cleaning machine operators, tool and dye makers, vehicle washers, and equipment cleaners, are not regarded by the public as the least dangerous or lowest-cost occupations. Louma and colleagues (79), by studying the risk factors of lumbar disc degeneration demonstrable with magnetic resonance imaging (MRI) with special emphasis on occupational load and back accidents, found an increased risk for posterior disc bulges among carpenters and for anterior disc bulges among machine drivers, but decreased signal intensity was not related to occupation. In addition, they also showed that car driving was also associated with anterior disc bulges.

\section{Trucking and Warehousing}

Seated, whole-body vibration is most commonly implicated as contributing to the high incidence of occupational low back pain in workers of the trucking and warehousing industries $(69,95,108,111,125-129)$. Drivers are also exposed to other activities such as loading and unloading a truck and prolonged sitting, also considered risk factors. Kelsey (95) and Kelsey and Hardy (111) found that men truck drivers were more than four times more likely to develop a herniated disc than women. Rosegger and Rosegger (129) found that 70\% (61\% to 94\%) of a group of tractor drivers had premature degenerative changes in the vertebral column, as detected by radiologic changes, with a prevalence of findings increasing with years of tractor driving.

\section{Construction}

Construction workers such as carpenters, bricklayers, and unskilled workers perform heavy manual work, repetitive tasks and assume awkward working positions, or are exposed to whole-body vibration, or continuous carrying and lifting of heavy loads, which may cause biochemical and morphologic changes of the disc and vertebrae, contributing to higher incidence of low back pain (130-132). The prevalence of low back pain in people working in the construction industry was shown to be the highest in the United States (80). In fact, in a study of radiographically detectable degenerative changes of the lumbar spine among concrete reinforcement workers and house painters, disc space narrowing occurred at about 10 years and spondylophytes at about 5 years in concrete workers compared to house painters (132). Similarly, a Finnish study found a risk of disc prolapse among construction workers that was three times as high as that of white-collar employees (64). However, in a Hamburg construction worker study (130) authors found that the 12-month prevalence of low back pain was highest in painters $(57 \%)$, intermediate in concrete builders and brick layers (41\%), and lowest in carpenters, and unskilled workers (38\%). Leigh and Miller (78), in ranking of occupations, reported construction laborers, welders, stone cutters, and warehouse workers as the highcost occupations.

\section{Law Enforcement}

A significantly high incidence in the prevalence of back pain was reported among police officers who drive for a significant part of their working day compared with those who do not drive as part of their employment $(133,134)$. A survey of police officers in the United States found that all back injuries, including first-time back injury, were associated with overexertion and that work loss was associated with litigation (134). In contrast, Brown and coworkers (133) concluded that the prevalence of chronic 
or recurring low back pain since joining the Royal Canadian Police Force was 55\%, which was comparable with the lifetime prevalence reported for the general population.

\section{Health-Care Workers}

A multitude of studies concern low back pain in healthcare workers, specifically nurses and nurses' aides (135143). However, these studies do not allow definitive conclusions. Marras and colleagues (140), used two different models, the low-back-disorder-risk model and the biomechanical spinal-loading model, to study a variety of patient-handling tasks, and employed nine men and eight women participants, 12 of whom had experience in patient handling. Their results showed that patient handling was an extremely hazardous job with a substantial risk of causing a low back injury, whether with one or two patient handlers; they concluded that patient handling in real situations, such as in a nursing home, would be expected to be even worse. In a US study of occupational low back injury in a hospital employee population with epidemiologic analysis of multiple-risk factors of a high-risk occupational group, researchers found significant associations for history of low back pain or "slipped disc" by self report and for history of previous back injury (139). Other significant associated variables included working the day shift, single status, and low body weight (139). BieringSorensen (143) reported that nurses have the highest injury rates of any occupations in Denmark. In an analysis of over 3,000 nursing personnel, in Taiwan, risk factors for low back pain were age, stature, body weight, duration of work, work habits, and sitting posture, with a lifetime prevalence of low back pain of 78\% (137). Cooper and colleagues (141) reported that the most common mechanism of injury was transfer, followed by lifting.

\section{INDIVIDUAL FACTORS}

The individual factors considered to influence low back pain are heredity, age, sex, posture, body height and weight or body build, smoking, and physical fitness and sports activities.

\section{Genetic Predisposition}

Until 1995, structural and biochemical changes associated with disc degeneration were major aspects, making the disc a primary focus of diagnostic investigations and management interventions, except for occasional reports exploring several theories, including familial and genetic predisposition (144-153). There is evidence to suggest that there is a familial component to other types of low back pain, such as ankylosing spondylitis, scoliosis, and spondylolisthesis. A genetic component to disc pathology is suggested by animal models, including some breeds of dogs, and a particular species of mouse (151). Familial predisposition to disc herniation in pediatric populations, and familial association of lumbar disc disease and other ailments have been described (2, 146, 149, 150, 153-158). Nachemson (159), has suggested that environmentally or genetically induced premature aging changes may render the disc mechanically incompetent, creating abnormal motion patterns that subject various spinal structures to undue stress, causing pain. Videman and coworkers (160), studying associations between variations in the vitamin D receptor gene and measures of disc degeneration on MRI, in 85 pairs of monozygotic twins, discordant for exposure to common conditions suspected of affecting disc degeneration, concluded that, "Specific vitamin D receptor alleles were associated with intervertebral disc degeneration - demonstrating, for the first time, the existence of genetic susceptibility to this progressive, age-related degenerative process." Jones and coworkers (161) also found significant associations between allelic variation in the vitamin D receptor gene and the presence of disc narrowing; found strong associations with the severity of osteophytosis, but only weak associations with the presence of osteophytes; and found no association with severity of disc narrowing or facet-joint arthritis. Annunen (162), studying mutation and intervertebral disc degeneration on MRI and CT scans in patients with sciatica, found strong association between collagen 9 gene mutation (Trp allele) with the presence of severe disc degeneration and sciatica, and gene allele associated with $4 \%$ of the patients with sciatica. Among other studies published in 1999, Bijkerk (163), in studying a population-based sample of 1583 individuals, compared variance in disc degeneration within and between sibling pairs, concluding that disc degeneration was significantly more common in siblings than in a random sample, signifying a genetic component of these problems. He explained that $75 \%$ of the variance in disc degeneration is by genetic factors. Similarly, Sambrook and colleagues (164), in a study of 172 monozygotic and 154 dizygotic twins, not selected for back pain or disc disease, compared MRI features of degenerative disc disease in the cervical and lumbar spines. They concluded that, for severe disc disease, inheritability in the lumbar spine was 64\%, as their results showed disc height, bulge, and osteophytes were heritable in the lumbar spine. Battié and coworkers (153) studied 115 male identical twin pairs who were selected based on lifetime discordance in sus- 
pected environmental risk factors for disc degeneration, and concluded that the disc degeneration may be explained primarily by genetic influences and by unidentified factors, which may include complex, unpredictable interactions. However, Heikkila and coworkers (152), in a nationwide Finnish cohort study of 9,365 adult twins, concluded that environmental factors explain more than $80 \%$ of the etiology of sciatica. Similarly, Videman and colleagues (158) also explained low back pain mostly based on environmental factors. Simmons and coworkers (165) indicated that a familial predisposition to degenerative disc disease can exist along with other risk factors. Similarly, Richardson and colleagues (166) concluded that familial predisposition toward lumbar disc pain and injury existed.

\section{Age}

Intervertebral discs undergo age-related degenerative changes that contribute to some of the most common causes of impairment and disability for middle-aged and older persons (Fig. 2). Aging is an evolutionary and dynamic process that results in degenerative changes, not only in the intervertebral discs, but also in ligaments and bones, accounting for most diseases and disorders of the aging spine (167). Kirkaldy-Willis and coworkers (168) described the pathogenesis of degenerative changes in the aging spine, entailing three phases, beginning with dysfunction and progressing to unstable and stabilizing phases, in the context of a three-joint complex that describes the articulation between two vertebrae as changes within each member of this joint complex will result in changes in others. Bernick and colleagues (169) investigated the age changes of the annulus fibrosus in human intervertebral discs and reported that age changes in the annulus were first observed in the vertebrae of persons aged 41 to 60 years and became progressively severe through advanced age (60 to 83 years).

Increasing age has been associated with an increase in musculoskeletal symptoms. A US national survey of physician visits among patients age 75 or older revealed that back pain is the third most frequently reported symptom in general and the most commonly reported in the musculoskeletal system (170). In another study, $17 \%$ of total back problem visits occurred in the 65-years-and-older age group (171, 172). A Canadian epidemiological report ranked back problems as the third leading cause of chronic health problems in the 65-years-and-older age category

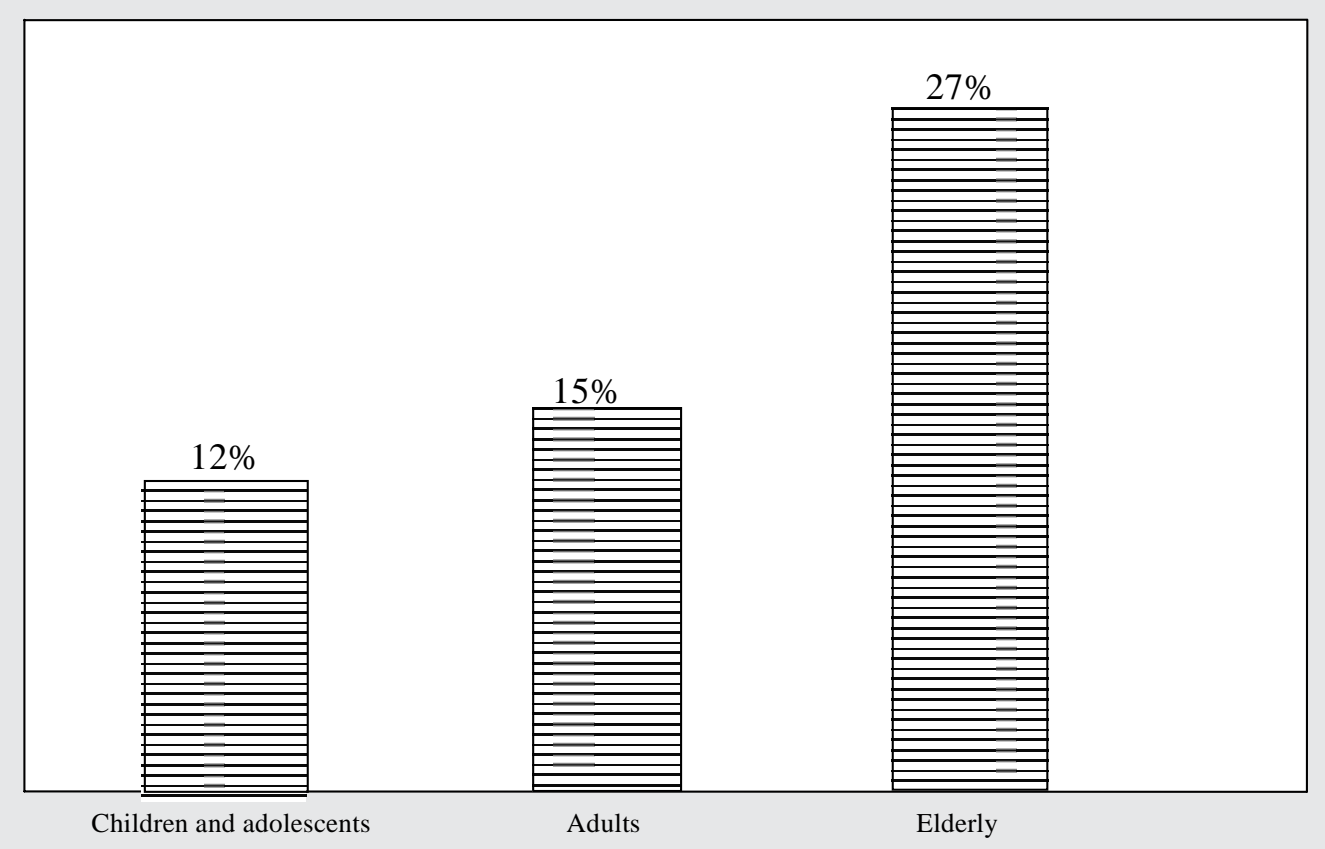

Fig. 2. Estimated average of age related prevalence of persistent low back pain. 
for women and the fourth leading cause of such problems for men in the same age category (173).

However, it has been stated that low back pain usually begins in early life, with highest frequency of symptoms occurring in the age range of 35 to 55; while sickness, absence, and symptom duration increase with increasing age $(33,90,174,175)$. The major studies and developments in the study of the epidemiology, diagnosis, and management of low back pain dealt and continued to deal with the specific problem of occupational low back pain. While the overall statistics of persons suffering from back pain are staggering, it has been shown that persons over 65 years of age experience low back pain with greater frequency and have been under-represented in research, as well as in management (7). A review of studies that evaluated pain in the elderly suggests that complaints of pain are more prevalent, varying from $44 \%$ to $84 \%$, in contrast to the general population, in which pain complaints are seen in $14 \%$ to $29 \%$ of the population (7). Similarly, the studies of back pain in childhood also indicate that low back pain has a relatively high prevalence during school years, which varies from country to country; with a $36 \%$ incidence in the United States; lowest incidence in Finland, with 20\%; and highest incidence in Switzerland, with $51 \%(8,176)$.

People age 65 and older are the fastest-growing segment of the population of not only the United States, but the entire world (7). By the year 2030, one of every five Americans will be 65 years or older; and by the year 2050 , almost 80 million Americans will be over 80 years of age (177). Bressler and colleagues (7) undertook a systematic review of the literature to determine the prevalence of low back pain associated with aging. A review of the litera- ture from 1966 through 1998 identified 152 articles describing the prevalence of back pain in the elderly, including only 12 articles for systematic review that met the inclusion criteria. Of these 10 dealt with cross-sectional and two dealt with cohort samples. In total, nine studies sampled individuals in the general community (178-186), two were derived from medical practices $(18,187)$, and one involved a long-term care facility (188). Bressler and coworkers (7) reported a prevalence of back pain among the elderly within the community ranging from $13 \%$ to $49 \%$; within the medical practice setting, the range was from $24 \%$ to $51 \%$; and in the long-term care setting, the prevalence was $40 \%$, concluding that there was an underrepresentation of the older population in the back pain literature, suggesting that the prevalence of low back pain in this population is not known with certainty and is not comparable with that in the younger population (Table 5).

Crook and colleagues (189) estimated that persistent pain has an incidence of $14 \%$, while age-dependent estimations varied from $8 \%$ for individuals between 10 and 30 years of age, to $40 \%$ in those over 81 years of age. Wood and Bradley (190) reported that, in the general population, at least $25 \%$ of the people who have serious impairment due to low back pain are over 65. Lavsky-Shulan and coworkers (182) found that low back pain was reported by approximately $24 \%$ of the women and $18 \%$ of the men in a study of rural elderly. Stelian and colleagues (191) reported that back pain resulting from osteoarthritis was a frequent occurrence in the elderly. Similarly, von Korff and colleagues (18) estimated that, among persons surviving to age $70,85 \%$ will experience back pain. Roy and Associates (192) reported the back "... as the most common area of pain location in the elderly." A high incidence of hospitalizations and spinal surgery was reported

Table 5: Prevalence of low back pain in the elderly.

\begin{tabular}{ccccc}
\hline Study Setting & $\begin{array}{c}\text { No. of } \\
\text { Studies }\end{array}$ & $\begin{array}{c}\text { Total Elderly } \\
\text { Population } \\
\text { Base }\end{array}$ & $\begin{array}{c}\text { Prevalence } \\
\text { Range }\end{array}$ & $\begin{array}{c}\text { Prevalence } \\
\text { Based on Total } \\
\text { Population }\end{array}$ \\
\hline Community $(178-186)$ & 8 & 16,694 & $\begin{array}{c}13 \% \text { to } \\
49 \%\end{array}$ & $24 \%$ \\
Primary care $(18,187)$ & 2 & 387 & $\begin{array}{c}23 \% \text { to } \\
51 \%\end{array}$ & $31 \%$ \\
Nursing home $(188)$ & 1 & 92 & $40 \%$ & $40 \%$ \\
\hline Total & $\mathbf{1 2}$ & $\mathbf{1 7 , 1 7 3}$ & $\mathbf{1 3 \% - 5 1 \%}$ & $\mathbf{2 7 \%}$ \\
\hline
\end{tabular}


in elderly Medicare beneficiaries, with an eight fold increase for spinal stenosis surgery from 1979 to 1992 (193). Apart from the pain from disc degeneration and facet-joint arthritis, the elderly suffer with a multitude of other degenerative disorders of the spine, as well as osteoporosis (194-196). The prevalence of osteoporosis is roughly one in four in women after the age of 50 and one in eight in men (195). The prevalence of vertebral fractures is $42 \%$ in women of advanced age and/or who have decreased bone mass (196). In addition, men also have painful and debilitating fractures of the spine, even though incidence is less than in women (195). A rapid rise of vertebral fractures in women is initially associated with the onset of menopause and is followed by an increase in the frequency of wrist and hip fractures due to age-related bone loss, whereas in men it is associated with fractures of the wrist and other bones due to osteoporosis (195).

The review of epidemiology of juvenile low back pain showed that studies indicate that the cumulative prevalence of low back pain in juveniles is close to $30 \%$, with increasing cumulative prevalence with age (8). Burton and coworkers (197), in a 5-year longitudinal interview and questionnaire-based survey of back pain in adolescents, reported that the annual incidence increased from $12 \%$ at age $12+$ to $22 \%$ at $15+$ years. Lifetime prevalence increased from $12 \%$ at age 11 to $50 \%$ at age $15+$ years. Others reported point prevalence of $17 \%$, with a lifetime prevalence of $30 \%$ to $57 \%$ in school children of low back pain (26). Tertti and colleagues (198) reported disc degeneration in $38 \%$ of the children with low back pain and $26 \%$ of the control subjects. Symptomatic adult disc protrusions were reported in less than $1 \%$ to $3 \%$ or more patients (199). In a prospective 9-year follow-up study involving randomized, matched subgroups of 15-year-old school children with or without low back pain at baseline, Salminen and colleagues (200) evaluated the long-term persistence of initially reported recurrent low back pain, showing that $35 \%$ of the participants in the original group with low back pain persistently reported recurrent pain. They reported the relative risk of recurrent low back pain up to the age of 23 years to be 16, compared with those having no disc degeneration. A study of familial and psychological factors of low back pain in school children by Balague and coworkers (201) showed that Swiss children reported a lifetime prevalence of back pain as $74 \%$. Balague and colleagues (202) also showed that the measured psychological factors were significantly associated with reported nonspecific low back pain and its consequences, as well as with sibling history of low back pain. Juvenile discogenic disease also has been reported com- monly. Heidhoff and colleagues (176) reported unexplained premature degeneration of the lower lumbar spine, a sevenfold increase in spondylolysis and spondylolisthesis in patients with juvenile discogenic disease. Salminen and coworkers $(203,204)$ reported that premature disc degeneration in adolescents was associated with recurrent back problems.

\section{Gender}

Health statistics routinely demonstrate that women have a higher morbidity from acute and nonfatal chronic diseases (205). Indeed, in most epidemiological pain research, women are more likely than men to report a variety of temporary and persistent pains, in addition to moderate or severe pains from menstruation, pregnancy, and childbirth (206). However, only small gender differences were reported in the majority of epidemiological investigations of the prevalence of low back pain. While many studies $(23,24,187,207-209)$ reported higher rates of incidence of low back pain in women, some studies found that men reported more low back pain at the time of the interview than women $(182,210)$. In spite of these differences in the reporting, it appears that the prevalence of back pain may be more strongly related to occupational factors than to gender (211). In addition, some back pain reported by women in epidemiological studies also may be associated with menstruation, pregnancy, or labor. It has also been shown that sciatica, which may affect $2 \%$ of the population with low back pain, was seen more frequently in men than women (5.3\% vs $3.7 \%$ ); and operations for disc herniation are performed about 1.5 to three times more often in men than in women $(212,213)$. Worker's Compensation claims and isthmic spondylolisthesis are more common in men than women $(206,207,213-215)$.

Back pain during pregnancy is also a frequent problem. Nine-month prevalence rates ranging from $48 \%$ to $90 \%$ have been reported, compared with the expected prevalence rate of $20 \%$ to $25 \%$, of nonpregnant women of the same age $(33,214-217)$. The back pain is attributed usually to increased biomechanical strain or an altered hormonal influence during pregnancy. An association between back pain during pregnancy and back pain later in life also has been claimed. In retrospective studies, $10 \%$ to $25 \%$ of the women with persistent low back pain refer the onset of back pain to pregnancy $(33,218)$. However, fortunately, herniated lumbar discs as the cause of pain are unusual; the prevalence of herniation is only one per 10,000 women $(214,219)$. In addition, imaging studies have reported the same prevalence of disc abnormalities 
and spondylolisthesis in pregnant and nonpregnant women $(220,221)$. In a prospective study, Kristiansson and colleagues (214), in a cohort of 200 consecutive women attending an antenatal clinic, reported back pain in $76 \%$ at some time during pregnancy and concluded that back pain during pregnancy was a common complaint, with $30 \%$ who presented with highest pain scores reporting greatest difficulties with normal activities. They also reported that back pain started early in pregnancy and increased over time, with higher prevalence with increasing pain intensity with duration, with increasing prevalence to $48 \%$ until the $24^{\text {th }}$ week, which remained stable and declined to 9.4\% after delivery (214). Oral contraceptives also have been incriminated as a causal factor of back pain in women. Wreje and coworkers (222) reported a significantly higher incidence of low back symptoms in contraceptive users, and they noted that pregnancy was not a confounding factor.

\section{Height}

A number of studies have shown that there is a relationship between the prevalence of low back pain and height $(65,88,96,123,223)$. The evaluations implicated height's contributing to higher-than-average risks of low back pain, which claim a clear-cut, direct relation between body height and the risk of sciatica from a herniated lumbar intervertebral disc, even though tallness does not seem to predict other types of low back pain $(65,88)$. Higher incidences of disc protrusions were also reported in taller children (224). However, some authors have reported no such correlation $(87,95)$.

\section{Weight}

Obesity is a serious medical problem that is increasing in prevalence, affecting millions, and of great interest to the public $(225,226)$. To articulate the burden of obesity, investigators have used indicators such as prevalence (226, 227), economic cost (228), and association with risk factors and diseases (229). Allison and colleagues (225) estimated the number of annual deaths attributable to obesity among US adults as approximately 280,000 based on hazard ratios from all subjects and 325,000 based on hazard ratios from only non-smokers and never-smokers. In addition to the deaths, obesity also has been associated with symptoms such as adverse fat distribution; and secondary disorders including coronary artery disease, stroke, non-insulin-dependent diabetes mellitus, cancer, and low back pain. There are several hypotheses relating to a link between obesity and low back pain. Increased mechani- cal demands resulting from obesity have been suspected of causing low back pain through excessive wear and tear, and it has also been suggested that metabolic factors associated with obesity may be detrimental (88, 95, 230-236). Obesity, defined as being $30 \%$ over ideal weight, influences normal body mechanics by making it more difficult to sit, stand, and walk and increases the time required to recover from an injury. Fatty tissue is a stress on the body even when a person is not injured, as it decreases the blood flow carrying nutrients for healing to the injured area. Since it is well known that too much fat is associated with loss of endurance, it is presumed that obesity also makes rehabilitation more difficult for the low back injury patient since poor endurance and cardiovascular fitness may hinder full participation in therapy (235). Thus, some consider obesity as a strong, contributing factor of low back pain $(95,237-242)$. While some consider it a possible, but not a particularly strong contributing factor of low back pain (243), others do not think it is a risk factor of low back pain $(244,245)$. In addition, it also has been postulated that obesity may be a marker (88) or a confounder $(230,232)$ for some other factors that are a true cause of low back pain.

Leboeuf-Yde (236) conducted a systematic review of epidemiologic literature to establish whether body weight is truly associated with low back pain and whether the link may be causal (Fig. 3). She reviewed 56 original research reports, reporting on 65 studies published between 1965 and 1997 , for the frequency of positive associations between body weight and low back pain and examined the presence of positive findings in relation to several study characteristics. The results of this review were that $32 \%$ of all the studies report a statistically significant positive weak association between body weight and low back pain. Similarly, among 111 low back pain variables defined in the 65 studies, a statistically significant positive association with weight or relative weight was reported for $25 \%$ or $23 \%$ of these 111 different low back variables. LeboeufYde (236) concluded that, due to lack of evidence, body weight should be considered as a possible weak risk indicator, but there are insufficient data to assess whether it is a true cause of low back pain. Subsequently, she evaluated only the studies as the sample size had the largest effect, using larger study samples of 3,000 or more, and in order to avoid the "healthy worker" effect, studies emanating from the general population to establish causal relationship between low back pain and obesity. Among these eight studies $(34,55,232,234,246-249)$, six of these eight large population-based studies reported at least one positive association between body weight and low back 
pain, for seven out of 12 different low back pain variables. Thus, the association between body weight and low back pain, when present in large, general population-based studies, was weak, with a rate ratio of less than two.

Lean and colleagues (242), in a cross-sectional study of approximately 13,000 (6,000 men and 7,000 women), aged 20 to 59 years, reported that chronic low back pain of more than 12 weeks per year was $14 \%$ in men with a normal waist circumference, compared to $20 \%$ and $21 \%$ with moderately and significantly larger waist circumference. Similarly, Han and colleagues (250), evaluating the prevalence of low back pain and associations with body fatness, fat distribution, and height, evaluated 5,887 men and 7,018 women aged 20 to 60 years. This study reported that women who are overweight or have a large waist have a significantly increased likelihood of low back pain. Obesity in relation to herniated lumbar intervertebral discs also showed conflicting results $(88,231,250)$. Han and coworkers (250) concluded that intervertebral disc-herniation symptoms were more common in women who were overweight or who had a larger waist circumference, whereas others also have found significant correlation between height and heavy body mass with intervertebral disc herniation $(88,231)$. O'Neill and coworkers (251), in a population-based survey, reported that increasing body mass index was associated with more frequent osteophytes at both the dorsal and lumbar spine, even though the relationship was stronger at the dorsal spine.

\section{Smoking}

Smoking of tobacco is considered as the single most preventable cause of death and disease in the United States (252). Even though the negative health consequences associated with cigarette smoking and the health benefits of quitting smoking are well established, approximately $26 \%$ of all adults in the United States continue to smoke; and recent estimates suggest that prevalence is increasing in youth. Klesges and colleagues (252) postulated that one of the many reasons that individuals begin to smoke is the perception that smoking helps control body weight, which is more widely held by young people and women, even though this is a false assumption. In an experimental ani-

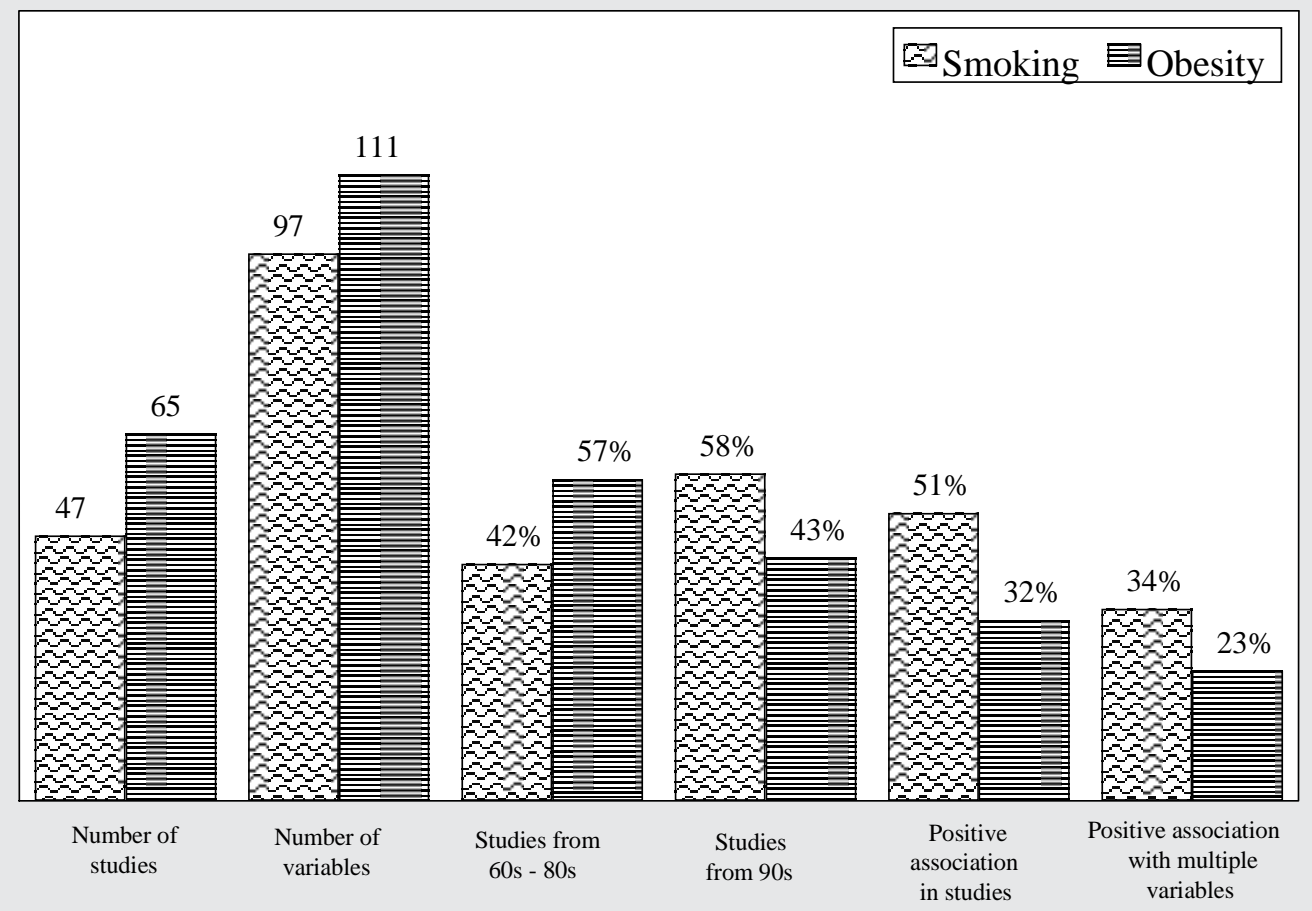

Fig. 3. Strength of association of smoking (11 large studies), and obesity (8 large studies) with low back pain

Adapted and modified from Leboedf-Yde C $(236,261)$ 
mal study, Holm and Nachemson (253) suggested that cigarette smoking not only significantly affects the circulatory system outside the intervertebral disc, where the most pronounced effect is the reduction in solute-exchange capacity, but also significantly deteriorates the cellular update rate and metabolic production within the disc. In another study evaluating the effect of smoking on intradiscal $\mathrm{pH}$ in rabbits, Hambly and Mooney (254) reported that cigarette smoking is an adverse event and will create a reduced $\mathrm{pH}$ in the rabbit's intervertebral disc. Battie and colleagues (255), in evaluating smoking and lumbar intervertebral disc degeneration in identical twins, showed that disc degeneration was $18 \%$ greater in the lumbar spines of smokers, as compared with nonsmokers. Others (66, 256) have shown significant correlation with intervertebral disc herniation and smoking. A suspected correlation between smoking and disc degeneration, with its potential to increase risk of low back pain, dated back to an epidemiologic study conducted by Gyntelberg in 1974 (223). Gyntelberg (223) postulated two different mechanisms linking smoking with low back pain, which included chronic bronchitis's inducing low back pain due to repeated increase of intraspinal pressure from coughing and aortic atherosclerosis, which may cause low back pain.

Leboeuf-Yde (257) conducted a systematic review of the epidemiologic literature on smoking and low back pain in which she reviewed 47 epidemiologic studies from 41 journal articles, published between 1974 and 1996 (Fig. 3). This review showed no consistency of statistically significant positive associations between smoking and low back pain. The association, when present, was usually weak and clearly apparent only in large study samples. LeboeufYde (257) reported at least one statistically significant positive association between smoking and low back pain in $51 \%$ of the studies. A statistically significant positive association with smoking was reported for $34 \%$ of the 97 different low back pain variables in the cross-sectional studies and for $35 \%$ of the 26 low back pain variables in the longitudinal studies. Sixty-four percent of the 11 larger studies with study samples of 3,000 or more had at least one significantly positive association, compared with $47 \%$ of the 36 smaller studies with samples of less than 3,000 $(34,55,69,223,232,234,247,249,258-260)$. This analysis showed consistent evidence in favor of a causal link between smoking and low back pain, which was present only in the study with the largest sample, ie, positive association, significant monotonic dose - response association, and signs of reversibility. Leboeuf-Yde (257) concluded that smoking should be considered a weak risk indicator and not a cause of low back pain.
Leboeuf-Yde and coworkers (261), in a cross-sectional postal survey of 29,424 people, aged 12 to 41 years, showed a positive association between smoking and low back pain that increased with the duration of low back pain. They concluded that there was a definite link between smoking and low back pain that increased with the duration and frequency of the low back pain problem, but the link was unlikely to be causal. Scott and colleagues (262) also studied the association between cigarette smoking and back pain in adults in a retrospective cohort study of adolescent idiopathic scoliosis. They reported statistically significant association between back pain and current cigarette smoking in the two groups of women and men with scoliosis, but not among men selected from the general population. They also concluded that the fact that smokers have more frequent episodes of back pain may imply that smoking exacerbates back pain, and the observation that stronger associations between back pain and smoking were found in the scoliosis cohorts suggests that smoking may have a greater impact on persons with damaged spines. However, some other studies showed these results, which are equivocal or even in disagreement with the above studies (79, 139, 263-265). In fact, Jamison and colleagues (266) revealed that patients with chronic low back pain who smoked had a need to smoke when they were in pain.

Feldman (267) in a prospective study concluded that smoking was found to increase the risk for low back pain in adolescents.

\section{Posture}

Postural deformities such as scoliosis, kyphosis, hyperlordosis, and leg-length discrepancy do not seem to predispose to low back pain in general $(90,174,175,233$, 268-272). Scoliosis, which was most vigorously investigated, showed no hard evidence of true association with low back pain, except in curves of $80^{\circ}$ or more $(123,271$ 273). Similarly, lordosis showed no correlation with the incidence of low back pain $(90,174)$. There have been numerous attempts to discover causative factors associated with low back pain resulting from unequal leg length. While the results of several studies suggest an inequality in leg length as a contributor to low back pain (274-279), other studies do not show any relation between leg-length inequality and low back pain or lumbar deformity (280282). Much of the uncertainty was attributed to lack of radiographic measurements to determine the leg length inequality. Most of the studies reporting lack of correla- 
tion between leg-length inequality and low back pain were done without radiologic measurements (90, 233, 270, 282), whereas studies with radiographic measurements have shown a relation between leg-length inequality and low back pain $(275,278)$. Soukka (280) measured leg-length inequality from radiographs and reported that this group of asymptomatic individuals did not differ from a group of persons who had disabling low back pain during the previous 12 months.

\section{Physical Activity}

Among the factors most commonly suspected of accelerating degenerative changes in the discs are various operational and leisure time physical-loading conditions. However, Porter (283) raised a different view that hard work could prevent disc protrusion by an adaptive increase in annular and ligamentous strength. It is also a common belief of physicians, as well as the general public and patients, that inactivity and lack of exercise increase the level of back pain, as well as disability. An alternate theory suggested that endurance exercises, such as running, may have positive nutritional effects on the disc by enhancing the transport of small solutes in and out of the disc (283, 284). Similarly, based on the "oxidative stress hypothesis of aging," physical activity increasing oxygen usage could be expected to accelerate degeneration $(285,286)$. Hence, a theoretical case can be made for both positive, as well as negative, effects of physical loading and exercise on disc degeneration. With similar mechanisms in mind, investigators also have studied the effects of participation in certain types of sports and exercise including football, golf, gymnastics, running, tennis, skiing, weight lifting, and other sports (284, 287-306). Videman and colleagues (288) studied the effects of extreme environmental sports and found greater disc degeneration in the lower lumbar levels of former elite athletes who had participated in soccer, which involves forceful bending, twisting, and occasional contact and falls; and throughout the entire lumbar spines of former competitive weight lifters, although the magnitude of the apparent effects of these exceptional loading conditions sustained over many years was small. In a study of elite cross-country skiers, it was shown that diagonal skiing style was the most common back-pain-inducing style, whereas no skier experienced back pain when skiing only (300). Ahrens (301) demonstrated reduction in vertebral column height, after a six-mile run and postulated that these findings have implications for physical therapy for patients with back pathology requiring an exercise program that may result in advice to limit running due to possible exacerbation of back symptoms. Sward and colleagues (302), investigating 142 top athletes representing wrestling, gymnastics, soccer, and tennis, reported high frequency of back pain $(50 \%$ to $85 \%)$. They also reported radiological abnormalities with reduced disc height, Schmorl's nodes, and change of configuration of vertebral bodies, which correlated with back pain in $36 \%$ to $55 \%$ of the athletes.

Generally, it is believed that persons with a good state of physical fitness appear to have a lesser risk of chronic low back pain and a more rapid recovery after an episode of acute back pain. Cady and colleagues $(303,304)$ reported that the firefighters who were judged to be the fittest had fewer injuries than the less fit ones. However, Dehlin and coworkers (305), in a randomized study of nursing aides, reported that fitness training improved fitness; however, there was no difference in the number of low back injuries, even though the fitness-trained nursing aides recovered more quickly after injury than the others. Several investigators have reported a higher incidence of low back pain and disc herniation in the population with a good physical exercise pattern, even though others reported the opposite results $(22,95,97,300,306)$.

\section{Marital and Social Factors}

Reisbord and Greenland (24), in a population-based study, analyzed the factors associated with self-reported back pain prevalence. Using gender, education, marital status, and age, the results showed: high prevalence, consisting of those 50- to 64-year-olds who were no longer married, regardless of education, with a prevalence of $44 \%$ to $46 \%$ for women and $42 \%$ for men; intermediate prevalence, consisting of 35- to 49-year-olds who were no longer married, regardless of education, with prevalence in women at $27 \%$ to $31 \%$, and in men at $23 \%$ to $27 \%$, and married persons with high school education or less, regardless of age, with prevalence in women of $9 \%$ to $31 \%$, and in men of $15 \%$ to $23 \%$; and low prevalence, consisting of those married with greater than a high school education, with prevalence in women of $13 \%$ to $15 \%$ and in men of $9 \%$ to $11 \%$, regardless of age, and 18- to 34-yearolds who were no longer married, with a prevalence in women of $13 \%$ to $17 \%$ and in men of $9 \%$ to $13 \%$, regardless of education. It has been speculated that working single mothers are at increasingly greater risk for developing medical illness such as cardiovascular disease than other groups in society, probably as a result of stress (307). Gatchel and colleagues (52) postulated that women with acute pain episodes who have a history of multiple childbirths are more likely to have a complaint of low back 
Table 6: Risk factors of low back pain.

\begin{tabular}{cccc}
\hline Causal & Probable & Possible & Nonrelated \\
\hline None & Genetic & Lifting & Body height \\
& Age & Vibration & Scoliosis \\
& Smoking & Psychosocial factors & Kyphosis \\
& Gender & Leg-length discrepancy \\
& Obesity & Physical activity \\
& Heavy physical work & \\
& Static work postures & \\
& Back pain history &
\end{tabular}

Job dissatisfaction

symptoms, possibly because of the increased physical demands of lifting children, loss of abdominal muscular support, and pelvic ligamentous laxity. However, Gatchel and coworkers (52) actually showed a much higher number of married patients than divorced or single patients $(61 \%$ vs $39 \%$ ) and a higher number of patients with a high school degree (48\%), followed by some college-educated people (42\%), and only $10 \%$ with no high school degree. It also has been stated that the prevalence of low back pain may be slightly greater in those from a lower social class (9). These trends are probably due to very complex relationships among physical, psychosocial, and economic factors. However, it is not clear what aspects of work, social disadvantages, lifestyle, attitudes, and behavior influence this (9).

\section{History of Back Pain}

Individuals with a history of prior back pain are considered to be at risk of recurrent or persistent back pain. Both retrospective and prospective studies have demonstrated increased risk of experiencing episodes of low back pain in individuals with history of back pain $(36-43,120,308$, 309).

\section{CONCLUSION}

Low back pain continues to be an important clinical, social, economic, and public health problem, affecting the population of the United States and the entire world. Multiple studies have shown an incidence of recurrent or chronic low back pain at 3 months, 6 months, and 12 months to range from $35 \%$ to $79 \%$.

Risk factors of low back pain are many, but none are convincingly causal (Table 6). Probable risk factors include genetic factors, age, and smoking. Possible risk factors include back pain history, job dissatisfaction, heavy physical work, static work postures, lifting, vibration, obesity, and psychosocial factors.

It is amusing to note that so-called independent evaluators, insurance companies, and attorneys argue that back pain is because patients smoke, are too fat, are too tall, work in harmful occupations, and have psychological disturbances. However, there is no scientific proof of these assertions. In addition, this attitude inevitably implies that their back pain is beyond help, that there is nothing a person can do about it, and that physicians either cannot or do not want to help. Nevertheless, at the same time, epidemiology teaches us that personal risk factors such as smoking, obesity, lack of physical fitness, and multiple psychosocial factors are probably or possibly linked to back pain even though causality is not proven. Hence, it would be good medical practice to consider a multitude of risk factors based on evidence at its appropriate level of significance, rather than conjecture. Advising patients to stop smoking, exercise, avoid excessive weight, and improve psychosocial status for the purpose of maintaining good health is good medical practice, which may or may not help alleviate low back pain directly, but certainly may influence it indirectly. 


\section{REFERENCES}

1. Spitzer WO, Leblanc FE, Dupuis M (eds). Quebec Task Force on Spinal Disorders. Scientific approach to the assessment and management of activity-related spinal disorders: A monograph for clinicians. Spine 1987; (suppl) 12:1-59.

2. Deyo RA, Tsui-Wu YJ. Descriptive epidemiology of low back pain and its related medical care in the United States. Spine 1987; 12:264-268.

3. Lawrence RC, Helmick CG, Arnett FC. Estimates of the prevalence of arthritis and selected musculoskeletal disorders in the United States. Arthritis \& Rheumatism 1998; 41:778-799.

4. Gureje O, Von Korff M, Simon GE et al. Persistent pain and well being. A World Health Organization Study in Primary Care. JAMA 1998; 280:147-151.

5. Loney PL, Stratford PW. The prevalence of low back pain in adults. A methodological review of the literature. Physical Therapy 1999; 79:384-396.

6. Leboeuf-Yde C, Lauritsen JM. The prevalence of low back pain in the literature. A structured review of 26 Nordic studies from 1954 to 1993. Spine 1995; 20:2112-2118.

7. Bressler HB, Keyes WJ, Rochon PA et al. The prevalence of low back pain in the elderly. A systematic review of the literature. Spine 1999; 24:1813-1819.

8. Duggleby T, Kumar S. Epidemiology of juvenile low back pain. A review. Disabil Rehabil 1997; 19:505512.

9. Waddell G. The back pain revolution. Edinburgh, Churchill Livingston, 1998; pp 85-101.

10. Postacchini F. Results of surgery compared with conservative management for lumbar disc herniations. Spine 1996; 21:1383-1387.

11. Fritsch EW, Heisel J, Rupp S. The failed back surgery syndrome. Reasons, intraoperative findings, and longterm results: A report of 182 operative treatments. Spine 1996; 21:626-633.

12. Koes BW, Scholten RJPM, Mens JMA et al. Efficacy of epidural steroid injections for low back pain and sciatica. A systematic review of randomized clinical trials. Pain 1995; 63:279-288.

13. Turner JA, Ersek M, Herron L et al. Surgery for lumbar spinal stenosis, attempted meta-analysis of the literature. Spine 1992; 17:1-7.

14. Waddell G, Kummel EG, Lotto WN et al. Failed lumbar disc surgery and repeat surgery following industrial injury. J Bone Joint Surg (Am) 1979; 61:201207.

15. Davis H. Increasing rates of cervical and lumbar spine surgery in the United States, 1979-1990. Spine 1994; 19:1117-1124.

16. Gibson JNA, Grant IC, Waddell G. The Cochrane review of surgery for lumbar disc prolapse and degenerative lumbar spondylosis. Spine 1999; 24:18201832.
17. Leigh JP, Markowitz SB, Fahs M et al. Occupational injury and illness in the United States. Estimates of costs, morbidity, and mortality. Arch Inter Med 1997; 157:1557-1568.

18. Van Korff M, Dworkin SF, Le Resche L et al. An epidemiologic comparison of pain complaints. Pain 1988;32:173-183.

19. Bombardier C, Kerr MS, Shannon HS et al. A guide to interpreting epidemiologic studies on the etiology of back pain. Spine 1994; 19:2047S-2056S.

20. Rosecrance, JC, Cook TM, Zimmermann CL. Workrelated musculoskeletal symptoms among construction workers in the pipe trades. Work 1996; 7:13-20.

21. Guo HR, Tanaka S, Cameron LL. Back pain among workers in the United States. National estimates and workers at high risk. American Journal of Industrial Medicine 1995; 28:591-602.

22. Frymoyer JW, Pope MH, Clements JG et al. Risk factors in low back pain. An epidemiological survey. J Bone Joint Surg Am 1983; 65:218-218.

23. Nagi SZ, Riley LE, Newby LG. A social epidemiology of back pain in a general population. J Chronic Dis 1973; 26:769-779.

24. Reisbord LS, Greenland S. Factors associated with self-reported back pain prevalence. A populationbased study. J Chronic Dis 1985; 38:691-702.

25. Kelsey JL, Golden Al, Mundt DJ. Low back pain/ prolapsed lumbar intervertebral disc. Rheum Dis Clin North Am 1990; 163:699-715.

26. Olsen TL, Anderson RL, Dearwater SR et al. The epidemiology of low back pain in an adolescent population. Am J Public Health 1992; 82:606-608.

27. Nachemson AL. Newest knowledge of low back pain. A critical look. Clin Orthop 1992; 8-20.

28. Friberg S. Lumbar disc degeneration in the problem of lumbago sciatica. Bull Hosp Joint Dis 1954; 15:120.

29. Stevens RL, Ryvar R, Robertson WR et al. Biological changes in the annulus fibrosus in patients with low back pain. Spine 1982; 7:223-233.

30. Cassidy D, Carroll L, Cote P. The Saskatchewan Health and Back Pain Survey. Spine 1998; 23:18601867.

31. Barsky A, Borus A. Somatization and medialization in the era of managed care. JAMA 1995; 274: 19311934.

32. Hillman M, Wright A, Rajaratnam Get al. Prevalence of low back pain in the community. Implications for service provision in Bradford, United Kingdom. J Epidemiol Community Health 1996; 50:347-352.

33. Bierring-Sorensen F. Low back trouble in a general population of 30-, 40-, 50-, and 60-year-old men and women. Study design, representative years, and basic results. Dan Med Bull 1982; 29:289-299.

34. Shekelle PG, Markovich M, Louie R. An epidemiologic study of episodes of back pain care. Spine 1995; 20:1668-1673. 
35. Anderson GBJ, Svensson HO. The intensity of work recovery in low back pain. Spine 1983; 8:880-887.

36. Van Den Hoogen HJM, Koes BW, Deville W et al. The prognosis of low back pain in general practice. Spine 1997; 22:1515-1521.

37. Croft PR, Papageorgiou AC, Thomas E et al. Shortterm physical risk factors for new episodes of low back pain. Prospective evidence from the South Manchester Back Pain Study. Spine 1999; 24:1556-1561.

38. Carey TS, Evans A, Hadler N et al. Care-seeking among individuals with chronic low back pain. Spine 1995; 20:312-317.

39. Carey TS, Garrett JM, Jackman A et al. Recurrence and care seeking after acute back pain. Results of a long-term follow-up study. Medical Care 1999; 37:157-164.

40. Miedema HS, Chorus AMJ, Wevers CWJ et al. Chronicity of back problems during working life. Spine 1998; 23:2021-2029.

41. Van Korff M, Deyo R, Cherkin D et al. Back pain in primary care. Outcome at 1-year. Spine 1993; 18:855862.

42. Tomas E, Silman AJ, Croft PR et al. Predicting who develops chronic low back pain in primary care. A prospective study. Br Med J 1999; 318:1662-1667.

43. Jayson MIV. Why does acute back pain become chronic? Spine 1997; 10:1053-1056.

44. Klenerman L, Slade PD, Stanley IM et al. The prediction of chronicity in patients with an acute attack of low back pain in a general practice setting. Spine 1995 ; 20:478-484.

45. Hanvik LJ. MMPI profiles in patients with low back pain. J Consult Clin Psychol 1951; 15:350-353.

46. Polatin PB, Kinney RK, Gatchel RJ et al. Psychiatric illness and chronic low back pain. The mind and the spine-which goes first? Spine 1993; 18:66-71.

47. Wiltse LL, Rocchio PD. Preoperative psychological tests as predictors of success of chemonucleolysis in the treatment of low back pain. J Bone Joint Surg (Am) 1975; 57:478-483.

48. Wolkind SN, Forrest AJ. Low back pain. A psychiatric investigation. Postgrad Med J 1972; 48:76-79.

49. Troup JDG. Causes, prediction and prevention of back pain at work. Scand J Work Environ Health 1984; 10:419-428.

50. Roland M, Morris R. A study of the natural history of low-back pain. Spine 1983; 8:145-150.

51. Burton AK, Tillotson KM, Main CJ et al. Psychosocial predictors of outcome in acute and subchronic low back trouble. Spine 1995; 20: 722-728.

52. Gatchel RJ, Polatin PB, Mayer TG. The dominant role of psychosocial risk factors in the development of chronic low back pain disability. Spine 1995; 20:27022709.

53. Croft PR, Papageorgiou AC, Ferry S et al. Psychologic distress and low back pain. Evidence from a prospective study in the general population. Spine 1996; 20:2731-2737.

54. Waddell G. Keynote address for primary care forum. Low back pain. A twentieth century health care enigma. Spine 1996; 21:2820-2825.

55. Heliövaara M, Mäkelä M, Knekt $\mathrm{P}$ et al. Determinants of sciatica and low back pain. Spine 1991; 16:608-614.

56. Barnekow-Bergkvist M, Hedberg GE, Janlert U et al. Determinants of self-reported neck, shoulder, and low back symptoms in a general population. Spine 1998; 23:235-243.

57. Viikari-Juntura E, Vuori J, Silverstein BA et al. A life-long prospective study on the role of psychosocial factors in neck-shoulder and low-back pain. Spine 1991; 16:1056-1061.

58. Heliövaara M. Risk factors for low back pain and sciatica. Ann Med 1989; 21:257-264.

59. $\mathrm{Xu} \mathrm{Y,} \mathrm{Bach} \mathrm{E,} \mathrm{Orhede} \mathrm{E.} \mathrm{Work} \mathrm{environment} \mathrm{and} \mathrm{low}$ back pain: The influence of occupational activities. Occup Environ Med 1997; 54: 741-745.

60. Wickström G. Effect of work on degenerative back disease. A review. Scand J Work Environ Health (Suppl) 1978; 1:1-12.

61. Chaffin DB, Park KS. A longitudinal study of lowback pain associated with occupational weight lifting factors. Am Ind Hyg Assoc J 1973; 34:513-525.

62. Damkot DK, Pope MH, Lord J et al. The relationship between work history, work environment, and lowback pain in men. Spine 1984; 9:395-399.

63. Troup JDG. Relation of lumbar spine disorders to heavy manual work and lifting. Lancet 1965; 1:857861.

64. Heliövaara M. Occupation and risk of herniated lumbar intervertebral disc or sciatica leading to hospitalization. J Chronic Dis 1987; 40:259-264.

65. Hrubec Z, Nashold BS. Epidemiology of lumbar disc lesions in the military in World War II. Am J Epidemiol 1975; 102:366-376.

66. Kelsey JL, Githens PB, O'Connor T et al. Acute prolapsed lumbar intervertebral disc: An epidemiologic study with special reference to driving automobiles and cigarette smoking. Spine 1984; 9:608-613.

67. Riihimäki H, Wickström G, Hänninen K et al. Predictors of sciatic pain among concrete reinforcement workers and house painters. A five-year follow up. Scand $J$ Work Environ Health 1989; 15:415-423.

68. Biering-Sörensen F, Thomsen C. Medical, social, and occupational history as risk indicators for low-back trouble in a general population. Spine 1986; 11:720725.

69. Frymoyer JW, Pope MH, Constanza MC et al. Epidemiologic studies of low-back pain. Spine 1980; 5:419423.

70. Andersson GBJ. Epidemiologic aspects on low back pain in industry. Spine 1981; 6:53-60. 
71. Svensson HO, Andersson GBJ. Low back pain in forty to forty-seven year old men. Work history and work environment factors. Spine 1983; 8:272-276.

72. Hildebrandt VH. Back pain in the working population. Prevalence rates in Dutch trades and professions. Ergonomics 1995; 38:1283-1298.

73. Volinn E, Koevering DV, Loeser JD. Back sprain in industry. The role of socioeconomic factors in chronicity. Spine 1991; 16:542-548.

74. Cohen-Mansfield J, Culpepper WJ, Carter P. Nursing staff back injuries. Prevalence and costs in long-term care facilities. AAOHN J 1996; 44:9-17.

75. Fourtes LJ, Shi Y, Zhang M et al. Epidemiology of back injury in university nurses from review of workers' compensation records and a care-control survey. J Occup Med 1994; 36:1022-1026.

76. Klein BP, Jensen RC, Sanderson LM. Assessment of workers' compensation claims for back strains/sprain. J Occup Med 1984; 26:443-448.

77. Murphy PL, Volinn E. Is occupational low back pain on the rise? Spine 1999; 24:691-697.

78. Leigh JP, Miller TR. Ranking occupations based upon the costs of job-related injuries and diseases. J Occup Environ Med 1997; 39:1170-1182.

79. Luoma K, Riihimaki H, Raininko R et al. Lumbar disc degeneration in relation to occupation. Scand J Work Environ Health 1998; 24:358-366.

80. Behrens V, Seligman P, Cameron L et al. The prevalence of back pain, hand discomfort, and dermatitis in the U.S. working population. Am J Public Health 1994; 84:1780-1785.

81. Lloyd MH, Gauld S, Soutar CA. Epidemiologic study of low back pain in miners and office workers. Spine 1986; 11:136-140.

82. Tsai SP, Gilstrap El, Cowles SR et al. Personal and job characteristics of musculoskeletal injuries in an industrial population. J Occup Med 1992; 34:606-612.

83. Riihimäki H. Back pain and heavy physical work. A comparative study of concrete reinforcement workers and maintenance house painters. Br J Ind Med 1985; 42:226-232.

84. Lockshin MD, Higgins IT, Higgins MW et al. Rheumatism in mining communities in Marion County, West Virginia. Am J Epidemiol 1969; 90:17-29.

85. Burdorf A, Govaert G, Elders L. Postural load and back pain of workers in the manufacturing of prefabricated concrete elements. Ergonomics 1991; 34:909918.

86. Kumar S. Cumulative load as a risk factor for back pain. Spine 1990; 15:1311-1316.

87. Leigh JP, Sheetz RM. Prevalence of back pain among full-time United States workers. Br J Med 1989; 4:651657.

88. Heliövaara M. Body height, obesity, and risk of herniated lumbar intervertebral disc. Spine 1987; 12:469472 .
89. Thorbjörnsson CB, Alfredsson L, Fredriksson K et al. Physical and psychosocial factors related to low back pain during a 24-year period. A nested case-control analysis. Spine 2000; 25:369-375.

90. Hult L. Cervical, dorsal, and lumbar spine syndromes. Acta Orthop Scan 1954; 17:1-102.

91. Kroemer KH, Robinette JC. Ergonomics in the design of office furniture. Ind Med Surg 1969; 38:115125 .

92. Bergquist-Ullman M, Larsson U. Acute low back pain in industry. A controlled prospective study with special reference to therapy and confounding factors. Acta Orthop Scand 1977; 170:1-117.

93. Svensson HO, Andersson GBJ. The relationship of low-back pain, work history, work environment, and stress. A retrospective cross-sectional study of 38 to 34-year-old women. Spine 1989; 14:517-522.

94. Westrin CG. Low back pain sick-listing. A nosological and medical insurance investigation. Scand J Soc Med 1973; 7:1-116.

95. Kelsey JL. An epidemiological study of the relationship between occupations and acute herniated lumbar intervertebral discs. Int J Epidemiol 1975; 4:197-205.

96. Brown JR. Factors contributing to the development of low back pain in industrial workers. Am Industr Hyg Assoc J 1975; 36:26-31.

97. Magora A. Investigation of the relation between low back pain and occupation. 3. Physical requirements: Sitting, standing, and weight lifting. Ind Med Surg 1972; 41:5-9.

98. Daniel JW, Fairbank JC, Vale PT et al. Low back pain in the steel industry. A clinical, economic, and occupational analysis at a North Wales integrated steelworks of the British Steel Corporation. J Soc Occup Med 1980; 30:49-56.

99. Magora A. Investigation of the relation between low back pain and occupation. 4. Physical requirements: Bending, rotation, reaching, and sudden maximal effort. Scand J Rehabil Med 1973; 6:186-190.

100. Bigos SJ, Spengler DM, Martin NA et al. Back injuries in industry. A retrospective study. III. Employeerelated factors. Spine 1986; 11:252-256.

101. Troup JD, Martin JW, Lloyd DC. Back pain in industry. A prospective study. Spine 1981; 6:61-69.

102. Walsh K, Varnes N. Osmond CC et al. Occupational causes of low-back pain. Scand J Environ Health 1989; 15:54-59.

103. Seidel H, Heide R. Long-term effects of whole-body vibration: A critical survey of the literature. Int Arch Occup Environ Health 1986; 58:1-26.

104. Hulshof C, van Zanten BV. Whole body vibration and low back pain. A review of epidemiological studies. Int Arch Occup Environ Health 1987; 59:205-220.

105. Lings S, Leboeuf-Yde C. Whole body vibrations and low back pain. Ugeskr Laeger 1998; 160:4298-4301.

106. Bovenzi M, Hulshof CT. An updated review of epide- 
miologic studies on the relationship between exposure to whole-body vibration and low back pain (19861997). Int Arch Occup Environ Health 1999; 72:351365 .

107. Seidel H, Bluethner R, Hinz B. Effects of sinusoidal whole-body vibration on the lumbar spine. The stressstrain relationship. Int Arch Occup Environ Health 1986; 57:207-223.

108. Seidel H, Heide R. Long-term effects of whole-body vibration. A critical survey of the literature. Int Arch Occup Environ Health 1986; 58:1-26.

109. Gruber GJ. Relationships between Whole - Body Vibration and Mobility Patterns among Interstate Truck Drivers. Washington, DC, US Department of Health, Education, and Welfare, DHEW (NIOSH) Publication No. 77-167. 1976.

110. Wilder DG, Woodworth BB, Frymoyer JW et al. Vibration and the human spine. Spine 1982; 7:243-254.

111. Kelsey JL, Hardy RJ. Driving of motor vehicles as a risk factor for acute herniated lumbar intervertebral disc. Am J Epidemiol 1975; 102:63-73.

112. Aburdorf A, Zondervan H. An epidemiological study of low back pain in crane operators. Ergonomics 1990; 33: 981-987.

113. Krause N, Ragland DR, Greiner BA et al. Psychosocial job factors associated with back and neck pain in public transit operators. Scand J Work Environ Health 1997; 23:179-186.

114. Kumar A, Varghese M, Mohan D et al. Effect of wholebody vibration on the low back. A study of tractordriving farmers in north India. Spine 1999; 24:25062515.

115. Netterstrom B, Juel K. Low back trouble among urban bus drivers in Denmark. Scand J Soc Med 1989; 17: 203-206.

116. Raphael KG, Marback JJ. The back pain of bus drivers. Prevalence in an urban area of California. Spine 1992; 17:1481-1488.

117. Masset D, Malchaire J. Low back pain. Epidemiologic aspects and work-related factors in the steel industry. Spine 1994; 19:143-146.

118. Suadicani P, Hansen K, Fenger AM et al. Low back pain in steel plant workers. Occup Med 1994; 44:217221.

119. Spengler DM, Bigos SJ, Martin NA et al. Back injuries in industry. A retrospective study. I. Overview and cost analysis. Spine 1986; 11:241-245.

120. Bigos SJ, Battie MC, Spengler DM et al. A prospective study of work perceptions and psychosocial factors affecting the report of back injury. Spine 1991; 16:1-6.

121. Skovron ML, Szpalski M, Nordin M et al. Sociocultural factors in back pain: A population based study in Belgian adults. Spine 1994; 19:129-137.

122. Astrand NE. Medical, psychological, and social factors associated with back abnormalities and self re- ported back pain. A cross sectional study of male employees in a Swedish pulp and paper industry. $\mathrm{Br} \mathrm{J}$ Ind Med 1987; 44:327-336.

123. Battié MC, Bigos SJ, Fisher LD et al. Anthropometric and clinical measurements as predictors of industrial back pain complaints. A prospective study. J Spinal Disord 1990;3:195-204.

124. Manninen P, Riihimak H, Heliovaara M. Incidence and risk factors of low-back pain in middle-aged farmers. Occup Med (Lond) 1995; 45:141-146.

125. Magnusson ML, Pope MH, Wilder DG et al. Are occupational drivers at an increased risk for developing musculoskeletal disorders? Spine 1996; 21:710-717.

126. Vihko V, Hasan J. Biomedical aspects of low frequency vibration. A bibliography of reference. Work Envrion Health 1970; 7:91-107.

127. Kelsey JL, White AA III. Epidemiology and impact of LBP. Spine 1980; 5:133-142.

128. Troup JDG. Drivers back and its prevention. A review of the postural, vibratory, and muscular factors, together with the problem of transmitted road-shock. Appl Ergonomics 1978; 9:207-214.

129. Rosegger R, Rosegger S. Health effects of tractor driving. J Agric Eng Res 1960; 5:241-276.

130. Stürmer T, Luessenhoop S, Neth A et al. Construction work and low back disorder. Preliminary findings of the Hamburg Construction Worker Study. Spine 1997; 22:2558-2563.

131. Rothenbacher D, Breener H, Arndt V et al. Disorders of the back and spine in construction workers. Prevalence and prognostic value for disability. Spine 1997; 22:1481-1486.

132. Riihimaki H, Mattsson T, Zitting A et al. Radiographically detectable degenerative changes of the lumbar spine among concrete reinforcement workers and house painters. Spine 1990; 15:114-119.

133. Brown JJ, Wells GA, Trottier AJ et al. Back pain in a large Canadian police force. Spine 1998; 23:821-827.

134. Sullivan CSB, Shimizu KT. Epidemiological studies of work-related injuries among law enforcement personnel. J Soc Occup Med 1988; 38:33-40.

135. Videman T, Nurminen T, Tola $S$ et al. Low-back pain in nurses and some loading factors of work. Spine 1984; 9:400-404.

136. Dehlin O, Hedenrud B, Horal J. Back symptoms in nursing aides in a geriatric hospital. Scand J Rehabil Med 1976; 8:47-53.

137. Chiou WK, Wong MK, Lee YH. Epidemiology of low back pain in Chinese nurses. Int J Nurs Stud 1994; 31:361-368.

138. Burgmeier AC, Blindauer B, Hecht MT. Backache in a hospital environment: Epidemiologic aspects and the role of various risk factors. Rev Epidemiol Sante Publique 1988; 36:128-137.

139. Ryden LA, Molgaard CA, Bobbitt S et al. Occupational low-back injury in a hospital employee popula- 
tion. An epidemiologic analysis of multiple risk factors of a high-risk occupational group. Spine 1989; 14:315-320.

140. Marras WS, Davis KG, Kirking BC et al. A comprehensive analysis of low-back disorder risk and spinal loading during the transferring and repositioning of patients using different techniques. Ergonomics 1999; 42:904-926.

141. Cooper JE, Tate RB, Yassi A. Components of initial and residual disability after back injuries in nurses. Spine 1998; 23:2118-2122.

142. Tate RB, Yassi A, Cooper J. Predictors of time loss after back injury in nurses. Spine 1999; 24:1930-1936.

143. Biering-Sorensen F. Risk of back trouble in individual occupations in Denmark. Ergonomics 1985; 28:51-60.

144. Battié MC, Cherkin DC, Dunn R et al. Managing low back pain. Attitudes and treatment preferences of physical therapists. Phys Ther 1999; 74:219-226.

145. Battié MC, Haynor DR, Fisher LD et al. Similarities in degenerative findings in the lumbar MRI of identical twins. J Bone Joint Surg 1995; 77:1662-1670.

146. Postacchini F, Lami R, Pugliese O. Familial predisposition to discogenic low-back pain: An epidemiologic and immunogenetic study. Spine 1988; 13:14031406.

147. Matsui H, Tsuji H, Terahata N. Juvenile lumbar herniated nucleus pulposus in monozygotic twins. Spine 1990; 15:1228-1230.

148. Varlotta GP, Brown MD, Kelsey JL et al. Familial predisposition for herniation of a lumbar disc in patients who are less than twenty-one years old. J Bone Joint Surg (Am) 1991; 73A:124-128.

149. Matsui H, Terahata N, Tsuiji H et al. Familial predisposition and clustering for juvenile lumbar disc herniation. Spine 1992; 17:1323-1327.

150. Porter RW, Thorpe L. Familial aspects of disc protrusion. Orthop Trans 1986; 10:524.

151. Berry RJ. Genetically controlled degeneration of the nucleus pulposus in the mouse. J Bone Joint Surg 1993; 72:1533-1548.

152. Heikkila JK, Koskenvuo M, Heliövaara M et al. Genetic and environmental factors in sciatica. Evidence from a nationwide panel of 9,365 adult twin pairs. Ann Med 1989; 21:393-398.

153. Battié MC, Videman T, Gibbons LE et al. Determinants of lumbar disc degeneration. A study of relating lifetime exposures and magnetic resonance imaging findings in identical twins. Spine 1995; 20:2601-2612.

154. Cowell HR, Hall JN, MacEwen GD. Genetic aspects of idiopathic scoliosis. Clin Orthop 1972; 86:121-131.

155. Schlosstein L, Teraski PI, Bluestone R et al. HLA antigen and ankylosing spondylitis. N Engl J Med 1973; 288:704-706.

156. Wynne-Davis R, Scott JHS. Inheritance and spondylolisthesis. A radiographic family survey. J Bone Joint Surg 1979; 61:301-305.
157. Varughese G, Quartey GRC. Familial lumbar spine stenosis with acute disc herniation - Case reports of four brothers. J Neurosurg 1979; 51:234-236.

158. Videman T, Numminen M, Troup JDG. Lumbar spinal pathology in cadaveric material in relation to history of back pain, occupation, and physical loading. Spine 1990; 15:728-740.

159. Nachemson AL. The future of low back pain research. In Frymoyer JW, Gordon ST (eds). New Perspectives on Low Back Pain. Rosemont, AAOS, 1989.

160. Videman T, Leppavuori J, Kaprio J et al. Intragenic polymorphisms of the vitamin D receptor gene associated with intervertebral disc degeneration. Spine 1998; 23:2477-2485.

161. Jones G, White C, Sambrook P et al. Allelic variation in the vitamin D receptor, lifestyle factors, and lumbar spinal degenerative disease. Annals of Rheumatic Diseases 1998; 57:94-99.

162. Annunen S, Paassilta P, Lohiniva J et al. An allele of COL9A2 associated with intervertebral discs disease. Science 1999; 285:409-412.

163. Bijkerk C, Houwing-Duistermaat JJ, Valkenburg HA et al. Heritabilities of radiologic osteoarthritis in peripheral joints and of disc degeneration of the spine. Arthritis \& Rheumatism 1999; 42:1729-1735.

164. Sambrook PN, MacGregor AJ, Spector TD. Genetic influences on cervical and lumbar disc degeneration. A magnetic resonance imaging study in twins. Arthritis Rheum 1999; 42:366-372.

165. Simmons ED, Guntupalli M, Kowalski JM et al. Familial predisposition for degenerative disc disease. A case-control study. Spine 1996; 21:1527-1529.

166. Richardson JK, Chung T, Schultz JS et al. A familial predisposition toward lumbar disc injury. Spine 1997; 22:1487-1493.

167. Buckwalter JA. Aging and degeneration of the human intervertebral disc. Spine 1995; 20:1307-1314.

168. Kirkaldy-Wills WH, Wedge JH, Young-Hing K et al. Pathology and pathogenesis of lumbar spondylosis and stenosis. Spine 1978; 4:319-327.

169. Bernick S, Walker JM, Paule WJ. Age changes to the anulus fibrosus in human intervertebral discs. Spine 1991; 5:520-524.

170. Koch H, Smith MC. Office-based ambulatory care for patients 75 years old and over: National Ambulatory Medical Care Survey, 1980 and 1981. Advance data from vital and health statistics. National Center for Health Statistics (NCHS). No. 110. DHHS Pub. No. (PHS) 85-1250. Hyattsville, MD: Public Health Service, 1985; 110:1-14.

171. Cypress BK. Characteristics of physician visits for back symptoms. A national perspective. Am J Public Health 1983; 73:389-395.

172. Hart LG, Deyo RA, Cherkin DC. Physician office visits for low back pain. Frequency, clinical evaluation, and treatment patterns from a US national sur- 
vey. Spine 1995; 20:11-19.

173. Goel V, Iron K, Williams JI. Indicators of health determinants and health status. In Goel V, Williams JI, Anderson GM et al (eds). Patterns of Health Care in Ontario. The ICES Practice Atlas, ed. 2. Ottawa, Canadian Medical Association, 1996; pp 5-26.

174. Horal J. The clinical appearance of low back disorders in the city of Gothenburg, Sweden. Acta Orthop Scand 1969; 118:1-109.

175. Biering-Sorensen F. A prospective study of low back pain in a general population. I. Occurrence, recurrence, and etiology. Scand J Rehabil Med 1983; 15:71-79.

176. Heithoff KB, Gundry CR, Burton CV et al. Juvenile discogenic disease. Spine 1994; 19:335-340.

177. US Bureau of Census. Current population reports. Population projections of the US by age, sex, race, and Hispanic origin-1993 to 2050. US Government Printing Office, Washington, DC (years 2000-2050), 1993; pp 25-1104.

178. Badley EM, Tennant A. Changing profile of joint disorders with age. Findings from a postal survey of the population of Calderdale, West Yorkshire, United Kingdom. Ann Rheum Dis 1992; 51:366-371.

179. Bergstrom G, Bjelle A, Sorensen LB et al. Prevalence of symptoms and signs of joint impairment at age 79 . Scand J Rehabil Med 1985; 17:173-182.

180. Bergstrom G, Bjelle A, Sundh V et al. Joint disorders at age 70, 75, and 79 years. A cross-sectional comparison. Br J Rheumatol 1986; 23:333-341.

181. Isacsson A, Hanson BS, Ranstam J et al. Social network, social support, and the prevalence of neck and low back pain after retirement. A population study of men born in 1914 in Malmö, Sweden. Scand J Soc Med 1995; 23:17-22.

182. Lavsky-Shulan M, Wallace RB, Kohout FJ et al. Prevalence and functional correlates of low back pain in the elderly. The Iowa 65+ Rural Health Study. J Am Geriatr Soc 1985; 33:23-28.

183. March LM, Skinner J, Schwatz J et al. Musculoskeletal disability in an elderly population living independently. A random survey in the northern Sydney area. Aust NZ J Med 1992; 22:731.

184. Mobily PR, Herr KA, Clark MK et al. An epidemiologic analysis of pain in the elderly. The Iowa $65+$ Rural Health Study. J Aging Health 1994; 6:139-154.

185. Sternbach RA. Survey of pain in the United States. The Nuprin pain report. Clin J Pain 1986; 3:49-53.

186. Woo J, Ho SC, Lau J et al. Musculoskeletal complaints and associated consequences in elderly Chinese ages 70 years and over. J Rheumatol 1994; 21:1927-1931.

187. Andersson HI, Ejlertsson G, Leden I et al. Chronic pain in a geographically defined general population. Studies of differences in age, gender, social class, and pain localization. Clin J Pain 1993; 9:174-182.

188. Ferrell BA, Ferrell BR, Osterwell D. Pain in the nursing home. J Am Geriatr Soc 1990; 38:409-414.
189. Crook J, Rideout E, Browne G. The prevalence of pain complaints in a general population. Pain 1984; 18:299-314.

190. Wood PHN, Bradley EM. Back pain in the community. Clin Rheum Dis 1980; 6:3-11.

191. Stelian J, Gil L, Habot B et al. Improvement of pain in elderly patients with degenerative arthritis of knee treated with narrow band light therapy. J Am Geriatr Soc 1992; 40: 23-26.

192. Roy R, Thomas M, Makarenko P. A comparative study of Canadian non-clinical and British pain clinic subjects. Clin J Pain 1990; 6:276-283.

193. Oldrige NB, Yuan Z, Stoll JE et al. Lumbar spine surgery and mortality among medicare beneficiaries, 1986. Am J Public Health 1994; 8:1292-1298.

194. Manchikanti L. Chronic low back pain in the elderly. Part I. Am J Pain Man 1997; 7:104-117.

195. Iqbal MM. Osteoporosis. Epidemiology, diagnosis, and treatment. South Med J 2000; 93:2-19.

196. Melton LJ III, Kan SH, Frye MA et al. Epidemiology of vertebral fractures in women. Am J Epidemiol 1989; 129: 1000-1011.

197. Burton KA, Clarke RD, McClune TD et al. The natural history of low back pain in adolescents. Spine 1996; 21:2323-2328.

198. Tertti MO, Salminen JJ, Paajanen HE et al. Low back pain and disc degeneration in children: A case-control MR imaging study. Radiology 1991; 180:503-507.

199. Bradbury N, Wilson LF, Mulholland RC. Adolescent disc protrusions. A long-term follow-up of surgery compared to Chymopapain. Spine 1996; 21A:372-377.

200. Salminen J. The adolescent back. A field survey of 370 Finnish schoolchildren. Acta Paediatr Scand 1984; 315: 8-122.

201. Balagué F, Skovron ML, Nordin M et al. Low back pain in schoolchildren. A study of familial and psychological factors. Spine 1995; 20:1265-1270.

202. Balagué F, Dutoit G, Waldburger M. Low back pain in schoolchildren. An epidemiological study. Scan J Rehabil Med 1988; 20:175-179.

203. Salimenen JJ, Erkintalo MO, Pentti J et al. Recurrent low back pain and early disc degeneration in the young. Spine 1999; 24:1316-1321.

204. Salminen JJ, Pentti J, Terho P. Low back pain and disability in 14-year old schoolchildren. Acta Paediat 1992; 81:1035-1039.

205. Svensson HO, Andersson GBJ. Low back pain in forty to forty-seven year old men. I. Frequency of occurrence and impact on medical services. Scand J Rehabil Med 1982; 14:47-53.

206. Unruh AM. Gender variation in clinical pain experience. Pain 1996; 65:123-167.

207. Virta L, Ronnemaa T, Osterman K et al. Prevalence of isthmic lumbar spondylolisthesis in middle-aged subjects from eastern and western Finland. J Clin Epidemiol 1992; 45:917-922. 
208. Nohej1 J, Dostál C, Fáberová R et al. Preliminary results of an epidemiological study of pain in a Prague population. Czech Med 1987; 10:117-124.213A.

209. Pietri F, Leclerc A, Boitel L et al. Low back pain in commercial travelers. Scan J Work Environ Hlth 1992; 18:52-58.

210. Laslett M, Crothers C, Beattie P et al. The frequency and incidence of low back pain/sciatica in an urban population. NZ Med J 1991; 104:424-426.

211. De Girolamo G. Epidemiology and social costs of low back pain and fibromyalgia. Clin J Pain 1991; 7:S1S7.

212. Heliövaara M, Sievers K, Impivaara O et al. Descriptive epidemiology and public health aspects of low back pain. Am Med 1989; 21:327-333.

213. Heliövaara M, Knekt P, Aromaa A. Incidence and risk factors of herniated lumbar intervertebral disc or sciatica leading to hospitalization. J Chronic Dis 1987; 40:251-285.

214. Kristiansson P, Svärdsudd, K, von Schoultz B. Back pain during pregnancy. A prospective study. Spine 1996; 21:702-709.

215. Fung BK-P, Kwong CM-F, Ho ES-C. Low back pain of women during pregnancy in the mountainous district of central Taiwan. Chin Med J 1993; 51:103106.

216. Mantle MJ, Greenwood RM, Curry HLF. Backache in pregnancy. Rheumatology and Rehabilitation 1977; 16:95-101.

217. Nwuga VCB. Pregnancy and back pain among upper class Nigerian women. Aus J Phys 1982; 28:8-11.

218. Svensson HO, Andersson GBJ, Hagstad A et al. The relationship of low-back pain to pregnancy and gynecologic factors. Spine 1990; 15:371-375.

219. LaBan MM, Perrin JCS, Latimer FR: Pregnancy and herniated lumbar disc. Arch Phys Med Rehabil 1983; 64:319-321.

220. Weinreb JC, Wolbarsht LB, Cohen JM et al. Prevalence of lumbosacral intervertebral disc abnormalities on MR images in pregnant and asymptomatic nonpregnant women. Radiology 1989; 170:125-128.

221. Saraste H. Spondylolysis and pregnancy. A risk analysis. Acta Obstet Gynecol Scand 1986; 65:727-729.

222. Wreje U, Isacsson D, Aberg H. Oral contraceptives and back pain in women in a Swedish community. Int J Epidemiol 1997; 26:71-74.

223. Gyntelberg F. One year incidence of low back pain among residents of Copenhagen aged 40-59. Dan Med Bull 1974; 21:30-36.

224. Salminen J, Erkintalo-Tertti MO, Paajanen HEK. Magnetic resonance imaging findings of lumbar spine in the young. J Spinal Disord 1993; 6:386-391.

225. Allison DB, Fontaine KR, Manson JE et al. Annual deaths attributable to obesity in the United States. JAMA 1999; 282:1530-1538.

226. Flegal KM, Carroll MD, Kuczmarski RJ et al. Overweight and obesity in the United States. Prevalence and trends. 1960-1994. Int J Obes Relat Metab Disord 1998; 22:39-47.

227. Kuczmarski RJ, Carroll MD, Flegal KM et al. Varying body mass index cutoff points to describe overweight prevalence among US adults. NHANES III (1988 to 1994). Obes Res 1997; 5:542-548.

228. Allison DB, Zannolli R, Narayan KM. The direct health care costs of obesity in the United States. Am J Public Health 1999; 89:1194-1199.

229. Allison DB, Pi-Sunyer FX. Obesity treatment. Examining the premises. Endocrinol Pract 1995; 1:353364.

230. Aro S, Leino P. Overweight and musculoskeletal morbidity. A ten-year follow-up. Int J Obesity 1985; 9:267-275.

231. Böstman OM. Body mass index and height in patients requiring surgery for lumbar intervertebral disc herniation. Spine 1993; 18:851-854.

232. Deyo RA, Bass JE. Lifestyle and low back pain. The influence of smoking and obesity. Spine 1989; 14:501506.

233. Pope MH, Bevins T, Wilder DG et al. The relationship between anthropometric, postural, muscular, and mobility characteristics of males ages 18-55. Spine 1985; 10:644-648.

234. Wright D, Barrow S, Fisher AD et al. Influence of physical, psychological, and behavioral factors on consultations for back pain. Br J Rheumatol 1995; 34:156161.

235. Smith N. Nutrition and the athlete. Orthop Clin North Am 1983; 14:387-396.

236. Leboeuf-Yde C. Body weight and low back pain. A systematic literature review of 56 journal articles reporting on 65 epidemiologic studies. Spine 2000; 25:226-237.

237. Bergenudd H, Nilsson B, Uden A et al. Bone mineral content, gender, body posture, and build in relation to back pain in middle age. Spine 1989; 14:577-579.

238. White A, Panjabi M. Clinical biomechanics of the spine. Philadelphia, JB Lippincott, 1978, pp 329-336.

239. Pope M, Rosen J, Wilder D et al. The relation between biomechanical and psychological factors in patients with low-back pain. Spine 1980; 5:173-178.

240. Hanningan W, Elwood P, Henderson JP et al. Surgical results in obese patients with sciatica. Neurosurgery 1987; 20:896-899.

241. Weir B. Prospective study of 100 lumbosacral discectomies. J Neurosurg 1979; 50:283-289.

242. Lean MEJ, Han TS, Seidell JC. Impairment of health and quality of life in people with large waist circumference. Lancet 1998; 351:853-856.

243. Pope MH. Risk indicators in low back pain. Ann Med 1989; 21:387-392.

244. Hildebrandt VH. A review of epidemiological research on risk factors of low back pain. In Buckle PE (ed). Musculoskeletal Disorders at Work. London, Taylor and Francis, 1987; pp 9-16. 
245. Kelsey JL, Hochberg MC. Epidemiology of chronic musculoskeletal disorders. Ann Rev Public Health 1988; 9:379-401.

246. Rissanen A, Heliövaara M, Knekt P et al. Risk of disability and mortality due to overweight in a Finnish population. Br Med J 1990; 301:835-837.

247. Adera T, Deyo RA, Donatelle RJ. Premature menopause and low back pain. A population based study. Ann Epidemiol 1994; 4:416-422.

248. Croft PR, Rigby AS. Socioeconomic influences on back problems in the community in Britain. J Epidemiol Community Health 1994; 48:166-170.

249. Heiberg Endresen E. Pelvic pain and low back pain in pregnant women. An epidemiological study. Scand J Rheumatol 1995; 24:135-141.

250. Han TS, Schouten JS, Lean ME et al. The prevalence of low back pain and associations with body fatness, fat distribution, and height. Int J Obes Relat Metab Disord 1997; 21:600-607.

251. O'Neill TW, McCloskey EV, Kanis JA et al. The distribution, determinants, and clinical correlates of vertebral osteophytosis. A population based survey. J Rheumatol 1999; 26:842-848.

252. Klesges RC, Zbikowski SM, Lando HA et al. The relationship between smoking and body weight in a population of young military personnel. Health Psychology 1998; 17:454-458.

253. Holm A, Nachemson A. Nutrition of the intervertebral disc. Acute effects of cigarette smoking. An experimental animal study. Ups J Med Sci 1988; 93:9199.

254. Hambly MF, Mooney V. Effect of smoking and pulsed electromagnetic fields on intradiscal $\mathrm{pH}$ in rabbits. Spine 1992; 17:83-85.

255. Battie MC, Videman T, Gill K et al. Smoking and lumbar intervertebral disc degeneration. An MRI study of identical twins. Spine 1991; 16:1015-1021.

256. An HS, Silveri CP, Simpson JM et al. Comparison of smoking habits between patients with surgically confirmed herniated lumbar and cervical disc disease and controls. J Spinal Disord 1994; 7:369-373.

257. Leboeuf-Yde C. Smoking and low back pain. A systematic literature review of 41 journal articles reporting 47 epidemiologic studies. Spine 1999; 24:14631470.

258. Linton SJ. Risk factors for neck and back pain in a working population in Sweden. Work Stress 1990; 4:41-49.

259. Boshuizen HC, Verbeek JHAM, Broersen JPJ et al. Do smokers get more back pain? Spine 1992; 17:922926.

260. Bigos SJ, Battié MC, Fisher LD et al. A prospective evaluation of preemployment screening methods for acute industrial back pain. Spine 1992; 17:922-926.

261. Leboeuf-Yde C, Kyvik KO, Bruun NH. Low back pain and lifestyle. Part I. Smoking: Information from a population based sample of 29,424 twins. Spine 1998;
23:2207-2214.

262. Scott SC, Goldberg MS, Mayo NE et al. The association between cigarette smoking and back pain in adults. Spine 1999; 24:1090-1098.

263. Heliövaara M, Mäkelä M, Aromaa A et al. Low back pain and subsequent cardiovascular mortality. Spine 1995; 20:2109-21011.

264. Penttinen J. Back pain and risk of fatal ischaemic heart disease. 13-year follow up of Finnish farmers. $\mathrm{Br}$ Med J 1994; 309:1267-1268.

265. Penttinen J. Risk of myocardial infarction among subjects visiting a doctor because of back disorder. A case-control study in Finnish farmers. Spine 1995; 20:2774-2776.

266. Jamison RN, Stetson BA, Parris WCV. The relationship between cigarette smoking and chronic low back pain. Addict Behav 1991; 16:103-110.

267. Feldman DE, Rossignol M, Shrier I et al. Smoking: A risk factor for developing of low back pain adolescents. Spine 1999; 24:2492-2496.

268. Hansson T, Bigos S, Beecher P et al. The lumbar lordosis in acute and chronic low back pain. Spine 1985; 10:154-155.

269. Magora A. Investigation of the relation between low back pain and occupation. 7. Neurologic and orthopedic condition. Scand J Rehabil Med 1975; 7:146151.

270. Rowe ML. Low back pain in industry. A position paper. J Occup Med 1969; 11:161-169.

271. Collis DK, Ponseti IV. Long term follow-up of patients with idiopathic scoliosis not treated surgically. J Bone Joint Surg 1969; 51A:425-445.

272. Kostuik JP, Bentivoglio J. The incidence of low back pain in scoliosis. Spine 1981; 6:268-273.

273. Nilsonne U, Lundgren KD. Long-term prognosis in pathic scoliosis. Acta Orthop Scand 1968; 39:456465.

274. Rush WA, Steiner HA. A study of lower extremity length inequality. Am J Roentgenol 1946; 56:616-623.

275. Giles LGF, Taylor JR. Low-back pain associated with leg length inequality. Spine 1981; 6:510-521.

276. Nichols PJR. Shot-leg syndrome. Br Med J 1960; 1:1863-1865.

277. Biering-Sörensen F. Physical measurements as risk indicators for low-back trouble over a one-year period. Spine 1984; 9:106-119.

278. Friberg O. Clinical symptoms and biomechanics of lumbar spine and hip joint in leg length inequality. Spine 1983; 8:643-651.

279. Mahar RK, Kirby RL, MacLeod DA. Simulated leglength discrepancy: Its effect on mean center-of-pressure position and postural sway. Arch Phys Med Rehabil 1985; 66:822-824.

280. Soukka A, Alaranta H, Tallroth K et al. Leg-length inequality in people of working age. The association between mild inequality and low-back pain is questionable. Spine 1991; 16:429-431. 
281. Froh R, Yong-Hing K, Cassidy JD et al. The relationship between leg length discrepancy and lumbar facet orientation. Spine 1988; 13:325-327.

282. Grundy PF, Roberts CJ. Does unequal leg length cause back pain? Lancet 1984; 2:256-258.

283. Porter RW. Does hard work prevent disc protrusion? Clin Biomech 1987; 2:196-198.

284. Sward L, Hellstrom M, Jacobsson B et al. Disc degeneration and associated abnormalities of the spine in elite gymnasts. A magnetic resonance imaging study. Spine 1991; 16:437-443.

285. Jenkins RR, Goldfarb A. Introduction. Oxidant stress, aging, and exercise. Med Sci Sport Exerc 1993; 25:210212.

286. Sohal RS, Allen RG. Oxidative stress as a causal factor in differentiation and aging: A unifying hypothesis. Experimental Gerontology 1990; 25:499-522.

287. Granhed H, Morelli B. Low back pain among retired wrestlers and heavy weight lifters. Am J Sports Med 1988; 16:530-533.

288. Videman T, Sarna S, Battié MC et al. The long-term effects of physical loading and exercise lifestyles on back-related symptoms, disability, and spinal pathology among men. Spine 1995; 20:699-709.

289. O'Connor FG, Marlowe SS. Low back pain in military basic trainees. A pilot study. Spine 1993; 18:13511354.

290. Skov T, Borg V, Ørhede E. Psychosocial and physical risk factors for musculoskeletal disorders of the neck, shoulders, and lower back in salespeople. Occup Environ Med 1996; 53:351-356.

291. Goldstein JD, Berger PE, Windler GE et al. Spine injuries in gymnasts and swimmers. Am J Sport Med 1991; 19:463-468.

292. Mundt DJ, Kelsey JL, Golden AL et al. An epidemiologic study of sports and weight lifting as possible risk factors for herniated lumbar and cervical discs. The Northeast Collaborative Group on Low Back Pain. Am J Sports Med 1993; 21:854-860.

293. Eriksson K, Nemeth G, Eriksson E. Low back pain in elite cross-country skiers. A retrospective epidemiological study. Scan J Med Sci Sports 1996; 6:31-35.

294. Nadler SF, Wu KD, Galski T et al. Low back pain in college athletes. A prospective study correlating lower extremity overuse or acquired ligamentous laxity with low back pain. Spine 1998; 23:828-833.

295. Chard MD, Lachmann MA. Racquet sports. Patterns of injury presenting to a sports injury clinic. Br J Sports Med 1987; 21:150-153.
296. Haycock CE, Gillette JV. Susceptibility of women athletes in injury. Myths vs reality. JAMA 1976; 236:163-165.

297. Hutchinson MR, Laprade RF, Burnett QM et al. Injury surveillance at the USTA Boys' Tennis Championships. A 6-year study. Med Sci Sport Exerc 1995; 27:826-830.

298. Sward L, Eriksson B, Peterson L. Anthropometric characteristics, passive hip flexion, and spinal mobility in relation to back pain in athletes. Spine 1990; 15:376-381.

299. Wadley GH, Albright JP. Women's intercollegiate gymnastics. Injury patterns and "permanent" medical disability. Am J Sport Med 1993; 21:314-320.

300. Frymoyer JW, Pope MH, Kristiansen T. Skiing and spinal trauma. Clin Sports Med 1982; 1:309-318.

301. Ahrens SF. The effect of age on intervertebral disc compression during running. Orthop Sport Phys Ther 1994; 20:17-21.

302. Sward L, Hellstrom M, Jacobsson B et al. Back pain and radiologic changes in the thoracolumbar spine of athletes. Spine 1990; 15:124-129.

303. Cady LD, Bischoff DP, O'Connell ER et al. Strength and fitness and subsequent back injuries in fire fighters. J Occup Med 1979; 21:269-272.

304. Cady LD Jr, Thomas PC, Karwasky RJ. Program for increasing health and physical fitness of firefighters. J Occup Med 1985; 27:110-114.

305. Dehlin O, Berg S, Andersson GB et al. Effect of physical training and ergonomic counseling on the psychological perception of work and on the subjective assessment of low-back insufficiency. Scand J Rhabil Med 1981; 13:1-9.

306. Van der Linden SM, Fahrer H. Occurrence of spinal pain syndromes in a group of apparently healthy and physically fit sportsmen (Orienteers). Scan J Rheumatol 1988; 17:475-481.

307. Gatchel RJ, Baum A, Krantz D. Introduction to Health Psychology. New York, McGraw \& Hill, 1989.

308. De Girolamo G. Epidemiology and social costs of low back pain and fibromyalgia. Clin J Pain 1991; 7:1-7.

309. Von Korff M, Leresche L, Dworkin SF. First onset of common pain symptoms. Pain 1993; 55:251-258. 